\title{
An updated climatology of surface dimethlysulfide concentrations and emission fluxes in the global ocean
}

\author{
A. Lana, ${ }^{1}$ T. G. Bell, ${ }^{2}$ R. Simó, ${ }^{1}$ S. M. Vallina,${ }^{3}$ J. Ballabrera-Poy, ${ }^{1}$ A. J. Kettle, ${ }^{4}$ \\ J. Dachs, ${ }^{5}$ L. Bopp, ${ }^{6}$ E. S. Saltzman, ${ }^{7}$ J. Stefels, ${ }^{8}$ J. E. Johnson, ${ }^{9}$ and P. S. Liss ${ }^{2}$ \\ Received 19 April 2010; revised 2 September 2010; accepted 25 October 2010; published 29 January 2011.
}

[1] The potentially significant role of the biogenic trace gas dimethylsulfide (DMS) in determining the Earth's radiation budget makes it necessary to accurately reproduce seawater DMS distribution and quantify its global flux across the sea/air interface. Following a threefold increase of data (from 15,000 to over 47,000) in the global surface ocean DMS database over the last decade, new global monthly climatologies of surface ocean DMS concentration and sea-to-air emission flux are presented as updates of those constructed 10 years ago. Interpolation/extrapolation techniques were applied to project the discrete concentration data onto a first guess field based on Longhurst's biogeographic provinces. Further objective analysis allowed us to obtain the final monthly maps. The new climatology projects DMS concentrations typically in the range of $1-7 \mathrm{nM}$, with higher levels occurring in the high latitudes, and with a general trend toward increasing concentration in summer. The increased size and distribution of the observations in the DMS database have produced in the new climatology substantially lower DMS concentrations in the polar latitudes and generally higher DMS concentrations in regions that were severely undersampled 10 years ago, such as the southern Indian Ocean. Using the new DMS concentration climatology in conjunction with state-of-the-art parameterizations for the sea/air gas transfer velocity and climatological wind fields, we estimate that 28.1 (17.6-34.4) Tg of sulfur are transferred from the oceans into the atmosphere annually in the form of DMS. This represents a global emission increase of $17 \%$ with respect to the equivalent calculation using the previous climatology. This new DMS climatology represents a valuable tool for atmospheric chemistry, climate, and Earth System models.

Citation: Lana, A., et al. (2011), An updated climatology of surface dimethlysulfide concentrations and emission fluxes in the global ocean, Global Biogeochem. Cycles, 25, GB1004, doi:10.1029/2010GB003850.

\section{Introduction}

[2] The ocean surface plays an important role in the global biogeochemical cycle of sulfur. Oceanic dimethylsulfide (DMS) emission is the main natural source of atmospheric sulfur [Bates et al., 1992; Simó, 2001]. Once in the atmo-

\footnotetext{
${ }^{1}$ Institut de Ciencies del Mar, CSIC, Barcelona, Spain.

${ }^{2}$ School of Environmental Sciences, University of East Anglia, Norwich, UK.

${ }^{3}$ EAPS, MIT, Cambridge, Massachusetts, USA.

${ }^{4}$ Department of Earth Sciences, SUNY-Oswego, Oswego, New York, USA.

${ }^{5}$ IDAEA, CSIC, Barcelona, Spain.

${ }^{6}$ LSCE, IPSL, CNRS, CEA, UVSQ, Gif Sur Yvette, France.

${ }^{7}$ School of Physical Sciences, University of California, Irvine, California, USA.

${ }^{8}$ Laboratory of Plant Physiology, University of Groningen, Haren, Netherlands.

${ }^{9} \mathrm{JISAO}$, University of Washington, Seattle, Washington, USA.
}

Copyright 2011 by the American Geophysical Union. 0886-6236/11/2010GB003850 sphere, DMS is oxidized to form sulfuric and methanesulfonic acids, which contribute to new particle formation and growth to maintain the pool of cloud condensation nuclei $(\mathrm{CCN})$ that is necessary for cloud formation [Andreae and Crutzen, 1997]. The number of these small-sized atmospheric particles affects the radiation budget of the Earth, directly by scattering solar radiation and indirectly by influencing cloud microphysics and albedo [Andreae and Rosenfeld, 2008]. The CLAW hypothesis, acronym based on the initials of the authors surnames [Charlson et al., 1987], postulates a climate feedback loop between phytoplankton, DMS emissions, $\mathrm{CCN}$, and cloudiness. The feasibility of such a feedback loop at the local scale has been challenged by stateof-the-art atmospheric model outcomes showing limited new particle formation in the marine boundary layer (MBL). According to these models, DMS contribution to CCN numbers would only occur at large supraregional scales after long-range transport in the free troposphere and reentrainment into the MBL [e.g., Carslaw et al., 2010]. 
[3] The main precursor of DMS is the microalgal metabolite dimethylsulfoniopropionate (DMSP). Intracellular DMSP breakdown leads to the production of DMS by phytoplankton [Stefels et al., 2007]. Microalgae also release untransformed DMSP through exudation and mortality, and part of this dissolved DMSP is converted to DMS by extracellular and bacterial enzymes [Stefels and Dijkhuizen, 1996; Kiene et al., 2000; Yoch, 2002; Stefels et al., 2007; Vila-Costa et al., 2007; Howard et al., 2008]. DMS, in turn, is oxidized by photochemical reactions [Brimblecombe and Shooter, 1986; Toole et al., 2003] and metabolized by heterotrophic bacteria. Finally, only a small fraction of the DMS produced escapes to the atmosphere [Simó, 2001; Vila-Costa et al., 2006]. The tight coupling between DMS production and loss makes it challenging to study the driving factors and the dynamics of DMS emission from the ocean surface. However, large-scale observations of ocean surface DMS reveal macroscale patterns of variability such as a global proportionality between DMS concentration and average daily solar radiation in the surface mixed layer [Vallina and Simó, 2007]. This provides partial support for the CLAW hypothesis.

[4] The potentially significant role of DMS in climate regulation has encouraged the community to provide an accurate representation of both DMS seawater concentration and sea/air DMS flux distribution on a global scale. There have been multiple efforts to accurately represent the global DMS distribution. The main effort, initiated by A.J. Kettle and M.O. Andreae, was to compile a now freely available database using archived DMS measurements. The Global Surface Seawater DMS Database (GSSDD), currently maintained at the NOAA-PMEL, is constructed from data contributions by individual scientists and made available to the scientific community (http://saga.pmel.noaa.gov/dms/). The data are sparsely distributed in both space and time, as is shown in the DMS data footprint on the $1^{\circ} \times 1^{\circ}$ annual global map (Figure S1). ${ }^{1}$ The map shows that the coverage is not enough to resolve the global distribution of DMS on a monthly basis, whereas the importance of global emissions maps for climate models necessitates the formulation of a gridding procedure by the best means possible. Therefore, extensive data treatment or modeling is required to produce global DMS and emission fluxes climatologies from the database.

[5] Several methods have been proposed to obtain realistic global DMS distributions. Some of them rely on the relationship between the DMS concentration and other variables for which global distributions exist or can be modeled: Anderson et al. [2001] computed DMS from chlorophyll, light and nutrients; Simó and Dachs [2002] used a twoequation algorithm to derive surface DMS from surface chlorophyll $a$ and the mixed layer depth; Aumont et al. [2002] and Belviso et al. [2004a] developed nonlinear parameterizations to compute DMS from chlorophyll $a$ and an index representing the community structure of marine phytoplankton. Other approaches are totally or partially based on numerical models: Chu et al. [2003], Six and Maier-Reimer [2006], Kloster et al. [2006], Elliott [2009], Bopp et al.

\footnotetext{
${ }^{1}$ Auxiliary materials are available with the HTML. doi:10.1029/ 2010 GB003850.
}

[2008] and Vogt et al. [2010] used prognostic biogeochemical formulations for DMS production and removal processes within global ocean circulation models.

[6] The most widely used global DMS climatology, derived exclusively from the database, was published a decade ago (Kettle et al. [1999] and Kettle and Andreae [2000]; hereafter referred to as K99 and K00, respectively). The number of data used was initially 15,617 (K99), to which approximately 1,500 extra seawater DMS concentration measurements from the period 1996-1998 were added to produce an updated climatology (K00). Since then, the scientific community has worked with SOLAS Integration (Surface Ocean Lower Atmosphere Study, http://www.bodc. ac.uk/solas integration/) to update the database, increasing the number of DMS measurements in the ocean surface three fold (47,250 in April 2010). The aim of this work is to create an updated monthly DMS concentration climatology for the global ocean, and an associated DMS emission flux climatology. Objective data analysis and interpolation schemes in concert with current knowledge of ocean biogeochemistry and DMS dynamics have enabled the construction of a new climatology. Novel distribution patterns, differences with the original climatology, and the resulting reestimate of the global annual emission flux are discussed.

\section{Data and Methodology}

\subsection{Data}

[7] The data used (47,313 DMS seawater concentration measurements) are entirely from the Global Surface Seawater DMS Database (http://saga.pmel.noaa.gov/dms/) plus 63 additional measurements in the South Pacific [Lee et al., 2010], not included in the database. The data contributed by individual researchers have been collected between March 1972 and February 2009 (mostly since April 1980); see Table S1. The data consist of DMS measurements, reported in $\mathrm{nM}$, from depths of $0-10$ meters.

[8] There is no quality control in the database. This is worth stressing because there is no unification of the DMS measurement protocol, and very few intercalibration exercises have been conducted in the last 30 years. A number of sampling and analytical issues have been reported or communicated in recent years. For example, the use of $\mathrm{HgCl}_{2}$ as a sample preservative can result in anomalously high DMS values by transformation of DMSP into DMS [Curran et al., 1998]; or, in the presence of thick blooms of high DMSP producers like Phaeocystis sp., a lack of sample prefiltration may produce continuous and abundant DMS during purging [del Valle et al., 2009]. Despite these recognized concerns, information is still too sparse to provide robust criteria for the selection or elimination of historical data. Hence, no data from the database has been flagged. However, to avoid the undesirable effects that potentially erroneous and very high values might produce during the objective analysis, data that were above the 99.9 percentile are removed. The $0.1 \%$ eliminated were seawater DMS concentrations greater than $148 \mathrm{nM}$.

[9] To create the climatology we first stratified data according to the sampling month, and averaged to $1^{\circ} \times 1^{\circ}$ bins, which are the input to the objective analysis. If there was only 
one DMS datum within the $1^{\circ} \times 1^{\circ}$ square, the pixel value would be the value of that datum. The objective analysis scheme used is described by Barnes [1964], which is the same employed by K99 for DMS. This method is used as well by other authors for temperature, salinity, oxygen and nutrients in the last version of the World Ocean Atlas [Locarnini et al., 2010] and previous editions (WOA94, WOA98, WOA01, WOA05). The purpose of this method is to create a gridded field of a variable from sparse in situ data. A key element of the objective analysis is the firstguess field, which is subsequently corrected with the help of the available observations.

\subsection{First-Guess Fields: Provinces and Substitutions}

[10] As described by Daley [1993], there are several methods to obtain the continuous monthly background fields that will be subsequently reshaped with in situ data: an existing climatology, the short forecast of an assimilation model, or some optimum blend of the two. In our case, using the earlier K99 climatology was not appropriate because we were using all of those same data in the updated climatology, and also because we were aiming at improving the first guess fields of K99. The authors of the World Ocean Atlas [Locarnini et al., 2010] used a single annual analysis based on zonal annual means as the first guess field for all of the seasonal climatologies. In our case, however, data are so spaced out in distance and time that direct interpolation between local annual means without consideration of physical and biological regionalization of the oceans would produce anomalous geographical representation. Furthermore, regional DMS concentrations vary so much among months that it was considered more appropriate to construct monthly first guess fields. For this purpose we adopted K99's use of the Longhurst's division of the oceans into static biogeographic provinces [Longhurst, 1998], each representing an oceanic region with coherent biogeochemical characteristics (e.g., chlorophyll, nitrate, mixing, etc.) distinguishable from those of its neighbor regions. These, in their author's words, offer the degree of formalism and partition in a constantly changing system that helps us to comprehend changes in such a vastly complex interacting whole [Longhurst, 2007].

[11] The province approach, which has been helpful to partially overcome the problem of undersampling, also carries its own limitations. Provinces have been defined as static features in the sea, with well defined borders that do not shift from month to month. Satellite imagery reveals that provinces, as recurrent coherent features, do exist, but also show that they are dynamic. In recent years there have been multiple efforts to define dynamic ocean provinces based on satellite measurements [e.g., Devred et al., 2007; Alvain et al., 2008; Hardman-Mountford et al., 2008; Oliver and Irwin, 2008]. However, because of the impossibility to attribute historical DMS data to their contemporary dynamic provinces, we decided to stay with the static provinces.

[12] Therefore, we divided the oceans into the 54 biogeographic provinces proposed by Longhurst [1998] (see Table 1). The monthly mean DMS concentration was calculated for each province (Figure 1). White regions indicate provinces with not enough data $(<3)$. However, in order to create a complete climatology, these areas need to be given a first-guess concentration.

[13] As in K99, temporal interpolation and substitution schemes were employed to fill the gaps and solve this problem. Firstly, an annual cycle was generated using the monthly means for each ocean province. Where a monthly gap occurred, it was filled by interpolating from the adjacent months. The interpolation method was a piecewise cubic Hermite technique [Fritsch and Carlson, 1980]. If there were three or fewer measurements per month per province, these values were not taken into account to generate the temporal evolution because they would have a disproportionate influence on the creation of the first-guess field and, consequently, in the objective analysis. In provinces that lacked enough months with data to construct a robust annual mean, the temporal evolution of a similar province was used and scaled with the few data of the original province. Provinces with enough data to complete the annual cycle solely by interpolation were not substituted. We tried to ensure that as many provinces as possible in the first guess field represented the data from that province; substitution was applied to 10 provinces $(18 \%$ of the total; see Table 1$)$, whereas the provinces substituted in K99 were $52 \%$ of the total.

[14] The choice of each substitution province was a subjective process based on a combination of criteria: similarity of chlorophyll concentration patterns, latitude, geographical proximity, as well as the choice made by $\mathrm{K} 99$. The whole series of resulting annual cycles are shown in Figure 2. The coastal Atlantic provinces GUIN and GUIA were substituted by the large provinces that are directly adjacent, ETRA and WTRA, respectively. The Indian Ocean Coastal Biome contains very little data despite its relative importance: EAFR, REDS and INDE all do not have enough data and were substituted by ARAB, with the exception of EAFR, which was substituted by ISSG. In the Pacific Ocean, PSAW was substituted by PSAE as both are part of the Pacific Westerly Wind Biome and have more similarities than differences in terms of the annual cycles of mixed layer and euphotic depths, surface chlorophyll and primary productivity [Longhurst, 1998]. In equatorial regions, the coastal province CAMR was substituted by CCAL following K99. The provinces AUSE and SUND were merged together into a single region, which was then used to substitute for AUSW and NEWZ. TASM is substituted by SSTC. TASM is a very small province that has it own particularities [Longhurst, 1998] but is expected to be largely affected by the processes and characteristics of its neighbor SSTC.

\subsection{Objective Analysis}

[15] By filling the monthly gaps in the annual cycle for each province as described above, twelve global first-guess maps with the monthly mean DMS were constructed in each province. Transitions across province borders were smoothed using an unweighted 11 point filter based on the work of Shuman [1957].

[16] Cressman [1959] proposed an iterative application of this distance-weighted interpolation method, with successive corrections. We tested several variants, based either on single-pass analysis [Barnes, 1964], or multiple-pass analysis for successive corrections [Cressman, 1959; Barnes, 
Table 1. The Biogeochemical Provinces Suggested by Longhurst $[1998]^{\mathrm{a}}$

\begin{tabular}{|c|c|c|c|c|c|}
\hline Province Name & Acronym & Number & Number of Data & Number of Months & Shape Substitute \\
\hline S. Pacific Subtropical Gyre & SPSG & 37 & 3982 & 8 & - \\
\hline Subantarctic Water Ring & SANT & 52 & 4156 & 9 & - \\
\hline Antarctic & ANTA & 53 & 1035 & 8 & - \\
\hline South Atlantic Gyral & SATL & 10 & 1102 & 10 & - \\
\hline Indian S. Subtropical Gyre & ISSG & 23 & 367 & 6 & - \\
\hline S. Subtropical Convergence & SSTC & 51 & 820 & 12 & - \\
\hline Indian Monsoon Gyres & MONS & 22 & 266 & 9 & - \\
\hline N. Pacific Tropical Gyre (East) & NPTE & 38 & 933 & 10 & - \\
\hline Pacific Equatorial Divergence & PEQD & 40 & 2550 & 10 & - \\
\hline N. Pacific Tropical Gyre (West) & NPTW & 35 & 352 & 5 & - \\
\hline W. Pacific Warm Pool & WARM & 41 & 993 & 5 & - \\
\hline Boreal Polar & BPLR & 1 & 777 & 7 & - \\
\hline N. Pacific Equatorial Countercurrent & PNEC & 39 & 1114 & 9 & - \\
\hline Archipelagic Deep Basins & $\mathrm{ARCH}$ & 42 & 50 & 5 & - \\
\hline Austral Polar & APLR & 54 & 1310 & 8 & - \\
\hline N. Atlantic Tropical Gyral & NATR & 7 & 549 & 10 & - \\
\hline N. Pacific Transition Zone & NPPF & 34 & 331 & 7 & - \\
\hline Sunda-Arafura Shelves & SUND & 48 & 16 & 2 & $\mathrm{~b}$ \\
\hline N. Atlantic Subtropical Gyral (West) & NASW & 6 & 987 & 11 & - \\
\hline Western Tropical Atlantic & WTRA & 8 & 420 & 7 & - \\
\hline Eastern Tropical Atlantic & ETRA & 9 & 180 & 5 & - \\
\hline Caribbean & CARB & 17 & 599 & 7 & - \\
\hline N. Atlantic Subtropical Gyral (East) & NASE & 18 & 1226 & 9 & - \\
\hline N. Pacific Epicontinental Sea & BERS & 30 & 2708 & 7 & - \\
\hline E. Africa Coastal & EAFR & 24 & 195 & 2 & ISSG \\
\hline N. Atlantic Drift & NADR & 4 & 1304 & 9 & - \\
\hline NW Arabian Upwelling & ARAB & 26 & 149 & 7 & - \\
\hline Atlantic Arctic & ARCT & 2 & 858 & 8 & - \\
\hline Mediterranean Sea, Black Sea & MEDI & 16 & 623 & 11 & - \\
\hline Kuroshio Current & KURO & 33 & 1087 & 8 & - \\
\hline Pacific Subarctic Gyres (East) & PSAE & 31 & 745 & 9 & - \\
\hline California Current & CALC & 44 & 2118 & 9 & - \\
\hline Australia-Indonesia Coastal & AUSW & 29 & 7 & 1 & AUSE+SUND \\
\hline Humboldt Current Coastal & HUMB & 46 & 544 & 6 & - \\
\hline Atlantic Subarctic & SARC & 3 & 1403 & 5 & - \\
\hline Pacific Subarctic Gyres (West) & PSAW & 32 & 54 & 2 & PSAE \\
\hline NW Atlantic Shelves & NWCS & 15 & 2522 & 11 & - \\
\hline Tasman Sea & TASM & 36 & 116 & 1 & SSTC \\
\hline NE Atlantic Shelves & NECS & 11 & 2191 & 11 & - \\
\hline Guinea Current Coastal & GUIN & 13 & 30 & 3 & ETRA \\
\hline SW Atlantic Shelves & FKLD & 20 & 166 & 4 & - \\
\hline Central American Coastal & CAMR & 45 & 97 & 2 & CALC \\
\hline Guianas Coastal & GUIA & 14 & 20 & 1 & WTRA \\
\hline Brazil Current Coastal & BRAZ & 19 & 100 & 4 & - \\
\hline New Zealand Coastal & NEWZ & 50 & 6 & 1 & AUSE+SUND \\
\hline Benguela Current Coastal & BENG & 21 & 182 & 5 & - \\
\hline East Australian Coastal & AUSE & 49 & 26 & 2 & $\mathrm{~b}$ \\
\hline Gulf Stream & GFST & 5 & 231 & 7 & - \\
\hline China Sea Coastal & CHIN & 47 & 141 & 5 & - \\
\hline E. India Coastal & INDE & 27 & 88 & 2 & ARAB \\
\hline W. India Coastal & INDW & 28 & 93 & 9 & - \\
\hline Alaska Downwelling Coastal & ALSK & 43 & 4582 & 6 & - \\
\hline Eastern Canary Coastal & CNRY & 12 & 681 & 8 & - \\
\hline Red Sea. Persian Gulf & REDS & 25 & 11 & 1 & ARAB \\
\hline
\end{tabular}

${ }^{\mathrm{a}}$ In order of decreasing areal extent with their name, abbreviation, reference number in Figure 2, number of DMS data, number of months with DMS data, and, where appropriate, the province used as a substitute (see section 2.2 for details).

${ }^{\mathrm{b}}$ The annual pattern in these provinces was constructed by combining DMS data from AUSE and SUND provinces.

1994; Koch et al., 1983], and with different weight functions, different filters, and different radius of influence. The technique we found to be most appropriate was the one applied by K99, with a radius of influence of $555 \mathrm{~km}$ and a single-pass correction.

[17] Finally, the uniform-within-province global monthly maps (Figure S2) were updated with in situ data using the distance-weighted interpolation scheme of Barnes [1964].
This method determines the variable at grid points as the sum of the weighted values of the departures of individual in situ data to the first-guess field. The closer a data point is to a certain grid point, the greater the influence the datum exerts to the grid point (inversely proportional to the exponential of the square of the distance). The radius of influence was chosen to be $555 \mathrm{~km}$, so that data beyond that distance from the grid point were not taken into account. 

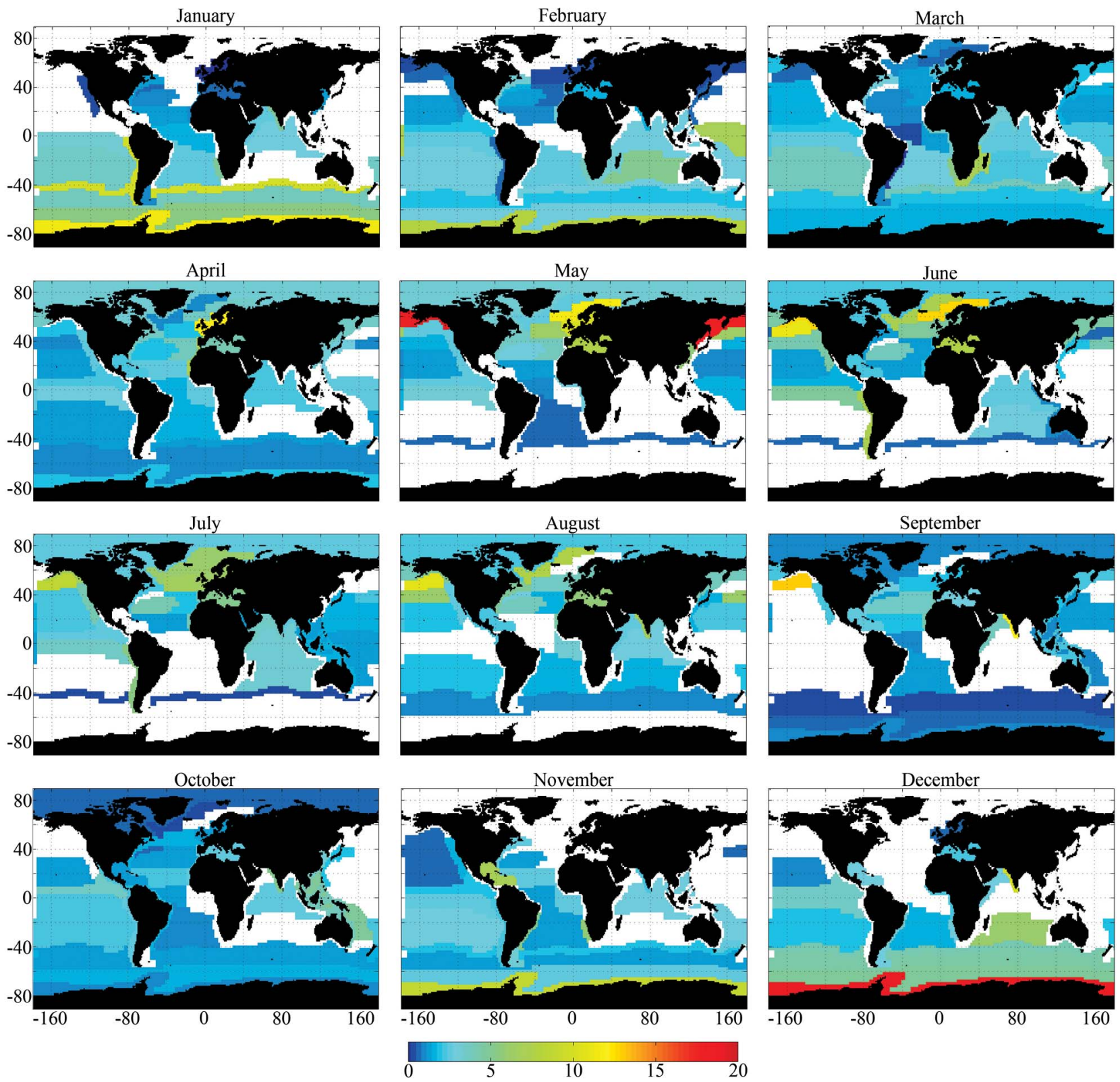

Figure 1. Monthly maps of average DMS concentrations (nM) for each biogeochemical province. Note that provinces that are white contain zero data for that calendar month.

[18] The resulting global map was once again smoothed by a 5 point median filter, and by a 11 point unweighted smoothing filter, with both filters applied following the methodology used in the World Ocean Atlas [Locarnini et al., 2010].

\subsection{Uncertainty}

[19] An estimate of the uncertainty in DMS concentration for each $1^{\circ} \times 1^{\circ}$ bin was made using the standard deviation (SD) of the log-transformed monthly observations for each biogeographic province that contained data. The mean value plus/minus the SD of the log-transformed data is hereafter referred to as the upper/lower "bounds," respectively. These
DMS concentration bounds for each month in each province thus capture approximately $68 \%$ of the available data and are asymmetric about the mean, which accurately reflects the positive skew in the data set distribution. For each month, in each province, the upper and lower bounds were normalized to the monthly average concentration and the mean of all of these taken to represent global average upper and lower bounds. The normalized average bounds were then applied to all provinces with months that contained $\leq 3$ data points and where a mean value had been interpolated or substituted. The interpolated or substituted mean value and the average normalized bounds were then used to 


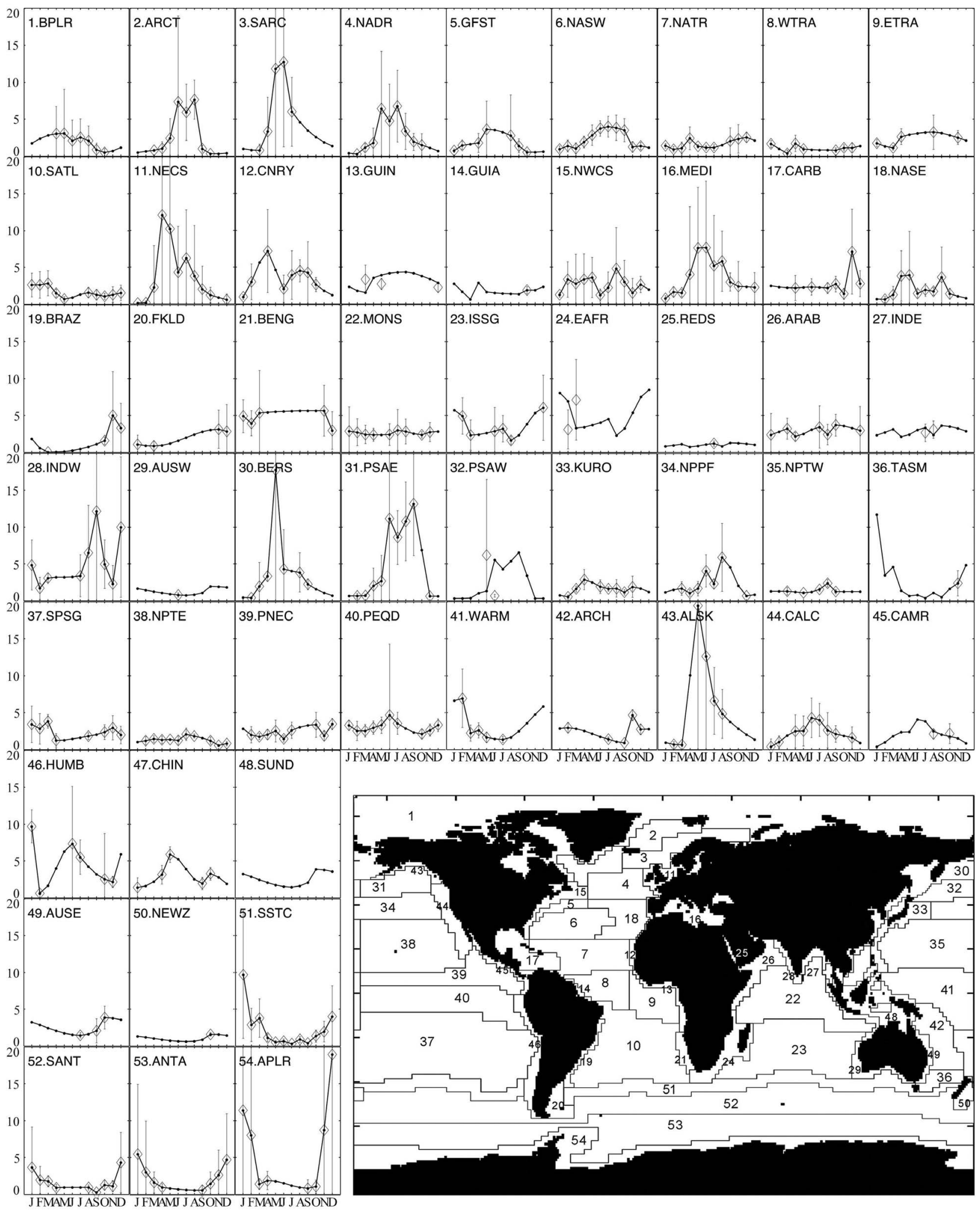

Figure 2. Time series of sea surface DMS concentration (nM) for each biogeochemical province. Calculated average values (open diamonds) plus one standard deviation are overlain with the seasonal cycle (dots and solid line) used to construct the L10 climatology. See text for details of interpolation and substitution methods. 
convert back to an appropriately scaled upper and lower bound for that specific month and province.

[20] In the substituted provinces, certain months still contained some data. Whenever processing these, the logtransformed SD was always applied to the substituted mean in preference to applying the global average bound values. After having produced bounds for all months in all provinces including all those that had been interpolated or substituted, the relative confidence in the mean values was assessed using the number of data points contained within each province in each month. Each upper and lower bound value was divided by the square-root of the number of data points (n). Provinces with months containing $\leq 3$ data points not used in the first-guess used $n=3$. We used these new climatologies of upper and lower bounds as a data-based estimate of uncertainty in the climatology. The monthly maps and related data will be available along with the concentration climatology itself on the SOLAS Project Integration Web site (http://www.bodc.ac.uk/solas_integration/ implementation_products/group1/\#dms).

\subsection{Other Ocean Variables}

[21] For the sake of statistical comparison with DMS distributions, state-of-the-art global climatologies of ocean variables were extracted and converted into $1^{\circ} \times 1^{\circ}$ monthly fields. The chlorophyll $a$ concentration climatology for the years 1997-2009 was obtained from the SeaWiFS Project (GSFC, NASA). Cumulative climatologies of phosphate and nitrate concentrations were obtained from the World Ocean Atlas 2009 [Garcia et al., 2010]. The SST climatology (1978-2008) was taken from the NCEP/NCAR reanalysis project, as above. The solar radiation dose (SRD) climatology was that computed by Vallina and Simó [2007]. The mixed layer depth (MLD) climatology was the same used by Vallina and Simó [2007] after modification of that by de Boyer-Montégut et al. [2004]. All data, including DMS, were log transformed before correlation to overcome nonnormal distribution.

\section{Results and Discussion}

\subsection{Data Distribution}

[22] The original data available to construct our revised DMS climatology (hereafter referred to as L10) were 47,313 surface seawater DMS concentration values, which were reduced to 47,266 after the data removal procedure described earlier. Although the time span of data collection is greater than three decades, more than half of the data are from the last 8 years. This is due to an obvious increase in the sampling effort, but also to the development of automatic and semiautomatic DMS analysis systems [e.g., Marandino et al., 2009; Saltzman et al., 2009; Archer et al., 2009]. The data are plotted in monthly $1^{\circ} \times 1^{\circ}$ fields. Even though the overall data is distributed fairly well throughout most of the global oceans, monthly distribution shows a remarkable lack of data in some regions and months: see Figure 1 and Table 1. As much as $64 \%$ of the data have been collected in the Northern Hemisphere, half of them during the boreal late spring and summer months (May-August). The Southern Hemisphere, despite its larger contribution to the global ocean surface area, contains only one third of the total data, with almost half of them collected during austral spring/ summer (November through February).

\subsection{DMS Correlation to Other Variables}

[23] An attempt was made to compare climatological DMS concentrations with other oceanic variables by means of Pearson's correlations of log transformed data. Due to the enormous number of data, all correlations were significant with probabilities $>99.99 \%$. Low negative correlations were found with surface nitrate and phosphate $(r=-0.09$ and -0.109 , respectively, $n=491,460)$. Low positive correlations were obtained with SST $(\mathrm{r}=0.181, \mathrm{n}=420,127)$ and chlorophyll $a(\mathrm{r}=0.147, \mathrm{n}=397,751)$, while much higher correlations were found with MLD $(\mathrm{r}=-0.47, \mathrm{n}=471,419)$ and SRD $(\mathrm{r}=0.58, \mathrm{n}=452,269)$. Kettle et al. [1999] also attempted correlation analyses with global climatologies, and found a similar result with chlorophyll $a$. They also found a negative correlation, yet lower, with the MLD, and a positive correlation with light, although they used surface irradiance rather than radiation dose. A remarkable difference between K99 and our study was the correlations to nitrate and phosphate, which were positive. It has to be stressed, however, that the data used by Kettle et al. [1999] were not $\log$ transformed despite the lack of normal distribution. The results of our correlation analysis support the suggestion (challenged by some authors [e.g., Derevianko et al., 2009]) that the MLD and the SRD play prominent roles in driving monthly surface DMS concentrations [Simó and Pedrós-Alió, 1999; Simó and Dachs, 2002; Vallina and Simó, 2007; Miles et al., 2009].

\subsection{Seasonal Cycles by Province}

[24] The high-latitude provinces in the North Atlantic and North Pacific Oceans (e.g., SARC, NADR, BERS, PSAE) show a common pattern of high average DMS concentrations $(>5 \mathrm{nM})$ during the boreal summer, with either unimodal or bimodal maxima between May and September (Figure 2). The Arctic Ocean (BPLR) exhibits a similar seasonal cycle, but with lower average maxima in spring/ summer $(<4 \mathrm{nM})$. Moving South toward northern temperate and subtropical provinces (e.g., NASW, NASE, NPPF, NPTW, NPTE), the seasonal pattern becomes less pronounced and the average spring/summer maximum concentrations are lower (generally $<5 \mathrm{nM}$ ). The seasonal cycle is almost lost in most of the tropical provinces around the equator in both hemispheres (e.g., NATR, WTRA, ETRA, MONS, NPTE, PNEC, PEQD, WARM), where average DMS concentrations are from moderate to low $(1-4 \mathrm{nM})$ throughout the year. The southern subtropical provinces of the Atlantic, Pacific and Indian Oceans (SATL, ISSG, SPSG) recover a slight seasonality with austral summer maxima at concentrations generally below $5 \mathrm{nM}$. The same seasonal pattern is much more pronounced in the four provinces of the Southern Ocean (SSTC, SANT, ANTA, APLR), with summer maxima occurring at concentrations of $5 \mathrm{nM}$ that peak most sharply in Antarctic waters (Figure 2). 

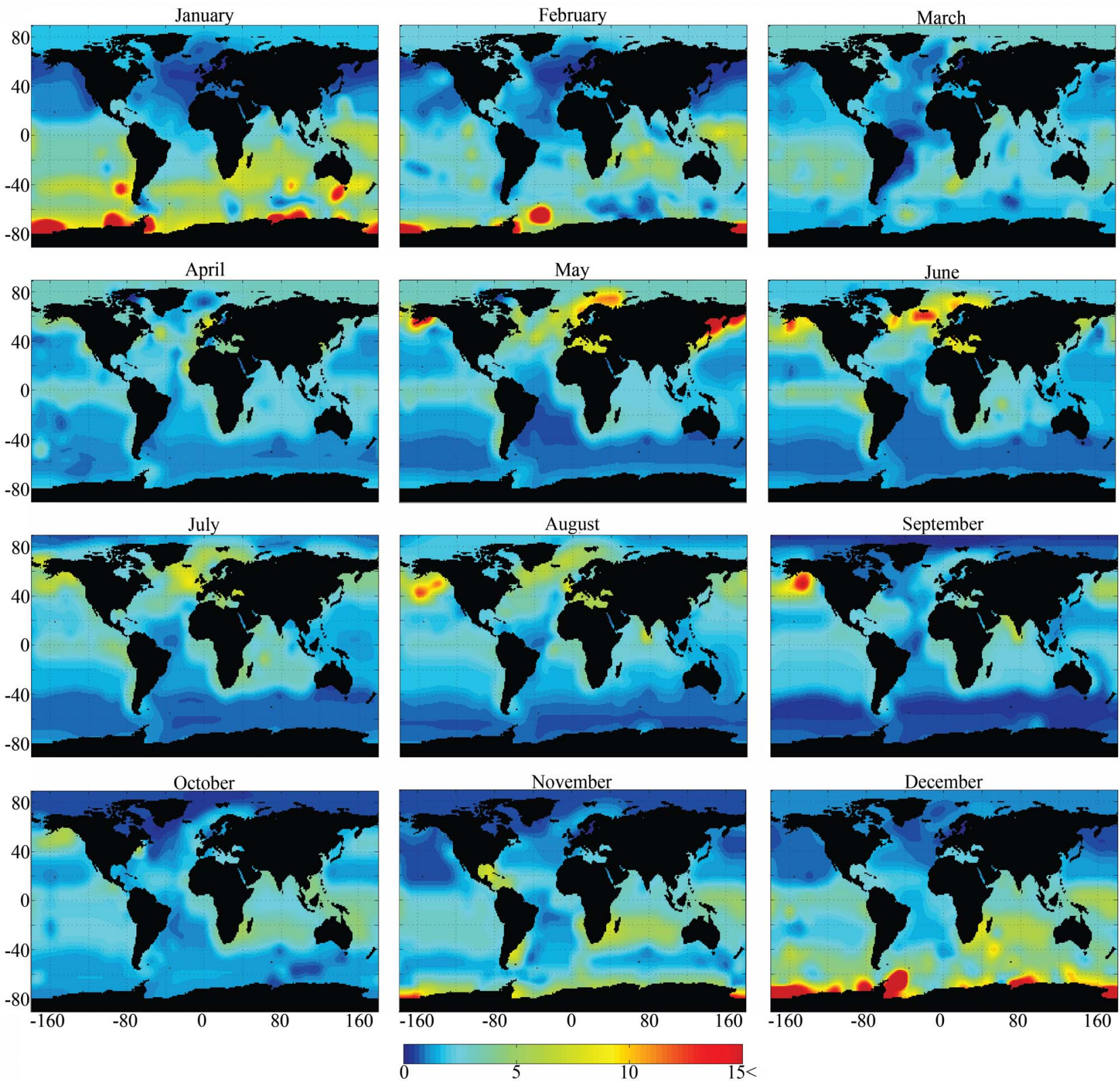

Figure 3. Monthly climatology (L10) of DMS concentrations (nM). Note that the scale is capped at $15 \mathrm{nM}$ to ensure readability of the plots, although only a few specific regions exceed $15 \mathrm{nM}$ DMS concentration.

\subsection{Monthly Global Distributions}

[25] The annual patterns shown in Figure 2 are used to create the monthly first-guess fields (see Figure S2). These are adjusted with real data at the local scale to obtain more realistic distributions. After 5 point median and 11 point unweighted filter smoothing, the monthly global maps of the climatology were produced (Figure 3). The remarkable spottiness of the maps is due to the differences between the first-guess background (which is the province monthly mean concentration) and the measurements made at the local scale. Spottiness must be regarded, hence, as a sign of fidelity to the measurements in the database.

[26] The monthly climatology maps (Figure 3) show the temporal (seasonal) and spatial variability of DMS concentrations. The salient features are (1) concentrations are in the range $1-7 \mathrm{nM}$ for the global oceans most of the time; only $1 \%$ of the climatology's values are $>10 \mathrm{nM}$ whereas $50 \%$ are $<2 \mathrm{nM}$, paralleling data distribution in the original database; (2) higher concentrations are found at high latitudes (polar and subpolar) and in some regions close to continents; (3) existence of a general trend toward increasing 
DMS concentration. Annual mean.

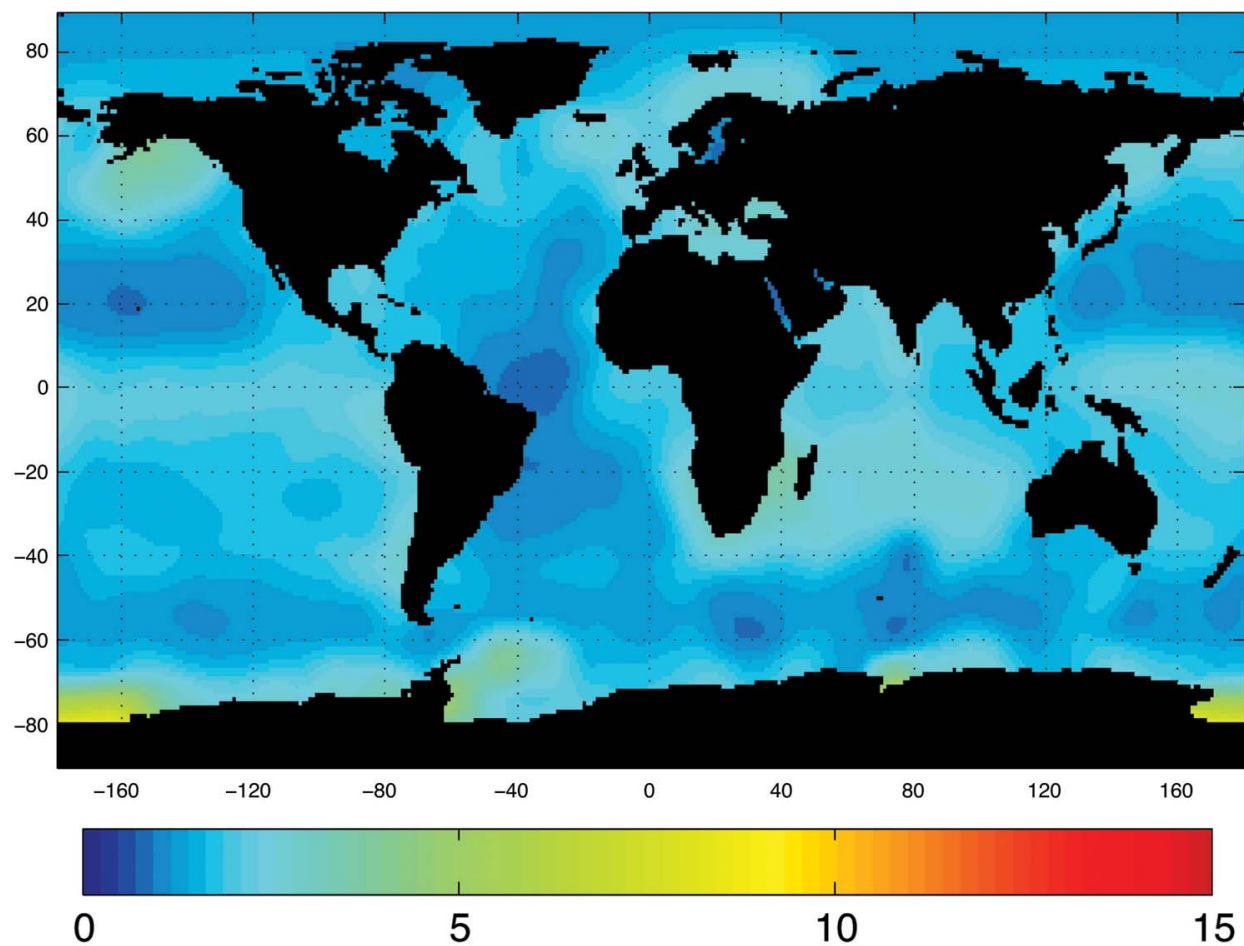

Figure 4. Annual global mean climatology (L10) of DMS concentrations (nM).

concentrations in summer in both hemispheres. The global map of annually averaged concentrations (Figure 4) is fairly homogeneous, with few regions with values below $1 \mathrm{nM}$ or above $5 \mathrm{nM}$.

\subsection{Regional Features}

[27] In the high-latitude Northern Hemisphere, DMS concentrations follow a strong seasonal pattern. They increase in the warmer and more illuminated months from late spring through late summer, although the timing of the concentration peak varies among regions (Figures 2 and 3). In the northern Gulf of Alaska and the Bering and Barents Seas, observed DMS is high in May, coinciding with documented blooms of strong DMS producers, Phaeocystis pouchetii and coccolithophores [Barnard et al., 1984; Iida et al., 2002; Matrai et al., 2007], and the summer maxima in June and July also accompanies the persistence of coccolithophores [Iida et al., 2002]. In the NW Atlantic and around the Iceland Basin, DMS concentrations are moderate in AprilMay and September and peak in June-July, at the time of maximum development of recurrent coccolithophore and flagellate blooms, which cooccur with dinoflagellates to yield high DMS concentrations [e.g., Matrai and Keller, 1993; Scarratt et al., 2007; Lizotte et al., 2008; Yang et al., 2009]. In the open ocean waters of the central Gulf of Alaska, concentrations are high throughout the summer and well into September for reasons not fully ascertained [Wong et al., 2005]. Much of the data from this latter region have been collected recently and thus summer DMS levels for the
PSAE province in our new climatology are remarkably higher than those in the original climatology, K99.

[28] Temperate low latitudes and northern subtropical regions typically follow a seasonal pattern with higher DMS concentrations in summer despite low chlorophyll $a$ concentrations, a feature that has been coined the "summer DMS paradox" [Simó and Pedrós-Alió, 1999]. In the large subtropical Pacific (NPTW, NPTE) the summer maximum occurs, yet very subtly. In the subtropical Atlantic there is a remarkable difference between the seasonality of the western side (NASW) and that of the eastern side (NASE). While in the NASW the summer maximum is clear [Dacey et al., 1998], in the NASE DMS concentrations are higher, yet more variable, in spring (April-May) than in late summer [Belviso and Caniaux, 2009].

[29] The eastern equatorial Pacific between $10^{\circ} \mathrm{N}$ and $10^{\circ} \mathrm{S}$ is one of the most visited regions over three decades. DMS concentrations in the region are relatively constant throughout the year [Bates and Quinn, 1997], which is clearly apparent in our climatological monthly maps. In the western equatorial Pacific, increased DMS concentrations in the period November-February have been observed, although it should be noted that the number of observations is low and the equatorial province (WARM) extends as far south as $18^{\circ} \mathrm{S}$. As in the Pacific, the main equatorial province of the Atlantic (WTRA) also does not show a marked seasonality. The neighboring eastern province, ETRA, has fewer data. There, higher DMS levels have been observed to occur between April and September, coinciding with climatological 
satellite observations of increased chlorophyll $a$ concentrations between June and September due to a strengthening of the zonal winds and associated upwelling [Pérez et al., 2005].

[30] The equatorial Indian Ocean (MONS) shows a slight trend toward higher DMS levels during the boreal summer. Concentrations are always above $2-3 \mathrm{nM}$ throughout the year. This is a remarkable difference with respect to the concentration given by K99, which was constructed almost without any data in this region and which predicted very low DMS levels over long periods of the year. The lack of data prompted K99 to attribute to MONS the patterns observed in the Arabian Sea (ARAB) and the coastal Indian provinces (INDE and INDW). The amount of data collected in MONS, ARAB and INDE has increased considerably in recent years. The new data demonstrates that DMS concentrations are typically elevated during the southwest monsoon (June to September), particularly on the West Indian shelf [Shenoy and Kumar, 2007]. On the eastern side of India, the few existing measurements in the Bay of Bengal point to more moderate concentrations all year round.

[31] The Indian subtropical gyre (ISSG) shows a marked seasonality with average DMS concentrations in the austral summer 6 times as high as the winter ones $(6$ and $1 \mathrm{nM}$, respectively). Such a seasonal pattern is coincident with that of the shoaling of the mixed layer and opposite to that of chlorophyll $a$ concentrations [Longhurst, 1998], thus setting the conditions for the so-called "summer DMS paradox" [Simó and Pedrós-Alió, 1999]. A noticeable increase in data coverage now provides a reasonably good description of DMS distribution in this large region. In K99, there were data only in two months and ISSG had to be substituted by its neighboring province to the South (SSTC), a region with completely different biogeochemistry. The semiempirical models of Aumont et al. [2002] and Simó and Dachs [2002] already predicted higher DMS concentrations in the southern Indian Ocean than K99. These predictions are borne out by the new climatology.

[32] The large ultraoligotrophic subtropical gyre provinces of the South Atlantic and South Pacific (SATL and SPSG) show a similar seasonality to ISSG, with higher DMS levels coincident with the shoaling of the mixed layer [Longhurst, 1998], yet with lower maximum concentrations [e.g., Bell et al., 2006]. It is worth mentioning that, in K99, both provinces had very little data and were adjusted to the seasonal pattern of the circumglobal province SSTC. Although in the last 10 years the number of measurements in these regions has increased considerably, SPSG is still one of the more poorly sampled open ocean regions (Table 1).

[33] DMS seasonality in the coastal Pacific upwelling region, Humboldt Current coastal province (HUMB), appears very marked but is highly uncertain because of the lack of data during half of the year. High, but variable, concentrations are found in June-July along the Peruvian coastal upwelling [Andreae et al., 1995], and low concentration levels are observed all along the province in OctoberNovember (J. Johnson, unpublished data, 2006, 2007) and in the southernmost part in February [Lee et al., 2010]. A very strong "hotspot" of DMS is apparent off the southern coast of Chile in January (Figure 3). Concentrations as high as $22 \mathrm{nM}$ were measured in a few samples through the transition between the HUMB and the South Subtropical Convergence province (SSTC). Since there was no associated signal in chlorophyll $a$, hydrography or atmospheric DMS concentrations, these observations may have corresponded to a highly localized patch [Marandino et al., 2009]. Further visits should help decipher if this hotspot is a recurrent feature.

[34] The Southern Ocean, as a whole, has enough data coverage to construct reliable monthly DMS maps. The seasonalities of the four provinces (SSTC, SANT, ANTA and APLR) are in phase, with concentrations increasing in the austral summer. High DMS levels (around $10 \mathrm{nM}$ ) are found southwest of Australia in January, coinciding with minimal mixed layer depths and maximal chlorophyll $a$ concentrations [Longhurst, 1998]. Moving southward, DMS levels decrease across the subantarctic current and increase again in Antarctic waters [McTaggart and Burton, 1992]. A similar pattern is found along transects from the subtropical convergence off South Africa or on either side of South America toward Antarctic waters [Liss et al., 2004]. The highest concentrations of the Southern Hemisphere (>20 nM) are found in Antarctic coastal seas (APLR) in the period November-February. Those high DMS values are driven by the strong phytoplankton blooms in the sea-ice breakout season [Trevena and Jones, 2006]. Throughout the rest of the year DMS concentrations are low, reflecting the low levels of biological activity due to increased ice cover and reduced light levels.

[35] Average summer DMS concentrations in Antarctic waters (APLR) have been reduced significantly with respect to those in K99. Ten years ago, average concentrations in December and January were larger than $40 \mathrm{nM}$ throughout most of the province, reaching regional maxima of up to $160 \mathrm{nM}$ (K99). With the recent increase in measurements, the new climatology contains a monthly average concentration of ca. $20 \mathrm{nM}$ in December, with a regional maximum of ca. $50 \mathrm{nM}$.

\subsection{Ocean-Atmosphere DMS Emission Fluxes}

[36] Ocean-atmosphere DMS fluxes are computed as the product of the air/sea concentration difference and gas transfer velocity, as follows: $\mathrm{F}=\mathrm{k}_{T}\left(C_{w}-C_{g} \alpha\right)$, where the gas transfer coefficient, $\mathrm{k}_{T}$, is the reciprocal of the total resistance to gas transfer on both sides of the air/sea interface [Liss and Slater, 1974]. DMS fluxes are generally parameterized assuming water side resistance only, but as demonstrated by McGillis et al. [2000], air side resistance can also be significant at cold temperatures and high wind speeds. Atmospheric DMS levels are typically orders of magnitude lower than those in the surface ocean, and are assumed to be zero for these calculations.

[37] The water side DMS gas transfer velocity was based on the $10 \mathrm{~m}$ wind-speed-based parameterization of Nightingale et al. [2000] (hereafter N00), for a Schmidt number of $600\left(\mathrm{k}_{600}=0.222 \mathrm{U}_{10}^{2}+0.333 \mathrm{U}_{10}\right)$. These were normalized to the Schmidt number of DMS as follows: $\mathrm{k}_{w}=\mathrm{k}_{600}\left(\mathrm{Sc}_{D M S} /\right.$ $600)^{-1 / 2}$, where $\mathrm{Sc}_{D M S}$ is a function of SST according to Saltzman et al. [1993].

[38] Total gas transfer velocities for DMS were computed using the atmospheric gradient fraction $\left(\gamma_{a}\right): \mathrm{k}_{T}=\mathrm{k}_{w}\left(1-\gamma_{a}\right)$, 
where $\gamma_{a}$ is defined by $\gamma_{a}=1 /\left(1+\mathrm{k}_{a} / \alpha k_{w}\right)$, using the approach of McGillis et al. [2000]. In this expression $\mathrm{k}_{a}$ is the airside transfer coefficient, which was based on neutral stability water vapor bulk transfer coefficients from Kondo [1975] and $\alpha$ is the DMS solubility, from Dacey et al. [1984].

[39] The DMS flux is calculated with the DMS concentration values obtained from this study and the total transfer velocity. This approach is slightly different than that of K00, who assumed only water side resistance to the air/sea flux under conditions of high wind speeds and cold SST. On an annual basis, the flux computed including air side resistance was $7.4 \%$ less than computed assuming water side resistance only.

[40] SST and wind speed climatologies were obtained from the NCEP/NCAR reanalysis project (http://www.esrl. noaa.gov/) for the period 1978-2008. Most of the DMS data used to generate the climatology were measured during that period. We applied a monthly sea-ice mask to set DMS emission fluxes to zero in ice-covered waters. Data on ice extent and concentration (percentage of the local ocean surface covered by sea ice) were provided by IFREMER/ CERSAT (http://cersat.ifremer.fr/) upon analyses of the $12.5 \mathrm{~km}$ resolution data from the US SSM/I sensor since 1992. We assumed negligible DMS emission fluxes where the sea ice concentration is higher than $75 \%$. All SST, wind speed and sea ice coverage data are converted to a $1^{\circ} \times 1^{\circ}$ resolution using a cubic spline interpolation that avoids the problem of distortions near the edges of the global map.

[41] Because $\mathrm{k}_{w}$ has a nonlinear dependence on wind speed, the use of monthly averaged wind speeds introduces a bias into the flux calculation. The flux was corrected for this effect assuming that instantaneous winds follow a Rayleigh distribution, using the approach of Simó and Dachs [2002]. To compare with K00, monthly global fields of DMS emission fluxes were also computed using the parameterizations of Liss and Merlivat [1986] and Wanninkhof [1992].

\subsection{Ocean-Atmosphere DMS Emission Fluxes}

[42] Ocean-atmosphere DMS fluxes are computed as the product of the air/sea concentration difference and gas transfer velocity, as follows: $\mathrm{F}=\mathrm{k}_{T}\left(C_{w}-C_{g} \alpha\right)$, where the gas transfer coefficient, $\mathrm{k}_{T}$, is the reciprocal of the total resistance to gas transfer on both sides of the air/sea interface [Liss and Slater, 1974]. DMS fluxes are generally parameterized assuming water side resistance only, but as demonstrated by McGillis et al. [2000], air side resistance can also be significant at cold temperatures and high wind speeds. Atmospheric DMS levels are typically orders of magnitude lower than those in the surface ocean, and are assumed to be zero for these calculations.

[43] The water side DMS gas transfer velocity was based on the $10 \mathrm{~m}$ wind-speed-based parameterization of Nightingale et al. [2000] (hereafter N00), for a Schmidt number of $600\left(\mathrm{k}_{600}=0.222 \mathrm{U}_{10}^{2}+0.333 \mathrm{U}_{10}\right)$. These were normalized to the Schmidt number of DMS as follows: $\mathrm{k}_{w}=\mathrm{k}_{600}\left(\mathrm{Sc}_{D M S} /\right.$ $600)^{-1 / 2}$, where $\mathrm{Sc}_{D M S}$ is a function of SST according to Saltzman et al. [1993].

[44] Total gas transfer velocities for DMS were computed using the atmospheric gradient fraction $\left(\gamma_{a}\right): \mathrm{k}_{T}=\mathrm{k}_{w}\left(1-\gamma_{a}\right)$, where $\gamma_{a}$ is defined by $\gamma_{a}=1 /\left(1+\mathrm{k}_{a} / \alpha k_{w}\right)$, using the approach of McGillis et al. [2000]. In this expression $\mathrm{k}_{a}$ is the airside transfer coefficient, which was based on neutral stability water vapor bulk transfer coefficients from Kondo [1975] and $\alpha$ is the DMS solubility, from Dacey et al. [1984].

[45] The DMS flux is calculated with the DMS concentration values obtained from this study and the total transfer velocity. This approach is slightly different than that of $\mathrm{K} 00$, who assumed only water side resistance to the air/sea flux under conditions of high wind speeds and cold SST. On an annual basis, the flux computed including air side resistance was $7.4 \%$ less than computed assuming water side resistance only.

[46] SST and wind speed climatologies were obtained from the NCEP/NCAR reanalysis project (http://www.esrl. noaa.gov/) for the period 1978-2008. Most of the DMS data used to generate the climatology were measured during that period. We applied a monthly sea-ice mask to set DMS emission fluxes to zero in ice-covered waters. Data on ice extent and concentration (percentage of the local ocean surface covered by sea ice) were provided by IFREMER/ CERSAT (http://cersat.ifremer.fr/) upon analyses of the $12.5 \mathrm{~km}$ resolution data from the US SSM/I sensor since 1992. We assumed negligible DMS emission fluxes where the sea ice concentration is higher than $75 \%$. All SST, wind speed and sea ice coverage data are converted to a $1^{\circ} \times 1^{\circ}$ resolution using a cubic spline interpolation that avoids the problem of distortions near the edges of the global map.

[47] Because $k_{w}$ has a nonlinear dependence on wind speed, the use of monthly averaged wind speeds introduces a bias into the flux calculation. The flux was corrected for this effect assuming that instantaneous winds follow a Rayleigh distribution, using the approach of Simó and Dachs [2002]. To compare with K00, monthly global fields of DMS emission fluxes were also computed using the parameterizations of Liss and Merlivat [1986] and Wanninkhof [1992].

\subsection{L10 Versus K00}

[48] In order to evaluate the influence of a 3-fold increase in measurements to the predicted monthly global distributions of DMS, we now compare the updated climatology (L10) with the reference climatology that is widely used at present (K00). The differences are summarized with graphical representations of the latitudinal annual means (Figure 5a) and the latitudinal means for the periods December-February (DJF) and June-August (JJA) (Figure 5b). Note that the concentration difference between K00 and L10 versus latitude can also be plotted for every individual month (see Figure S3). Large differences in the annual average distribution are found in the high latitudes $\left(\geq 65^{\circ}\right)$ of both summer hemispheres, where K00 predicted much higher DMS concentrations than L10. Clearly, the inclusion of new data has led to a substantial decrease of the high-latitude average DMS concentration, partly because data in K00 were dominated by coastal and ice-edge measurements.

[49] There are two latitudinal bands where L10 predicts higher annual mean concentrations than $\mathrm{K} 00$. One is around $50^{\circ}-60^{\circ} \mathrm{N}$, where the incorporation of a great number of measurements in the DMS-rich Alaska coastal province ALSK (J. Johnson et al., unpublished data, 2002, 2003) has increased the regional mean (Figure 2). The other band 
a) Latitudinal annual mean

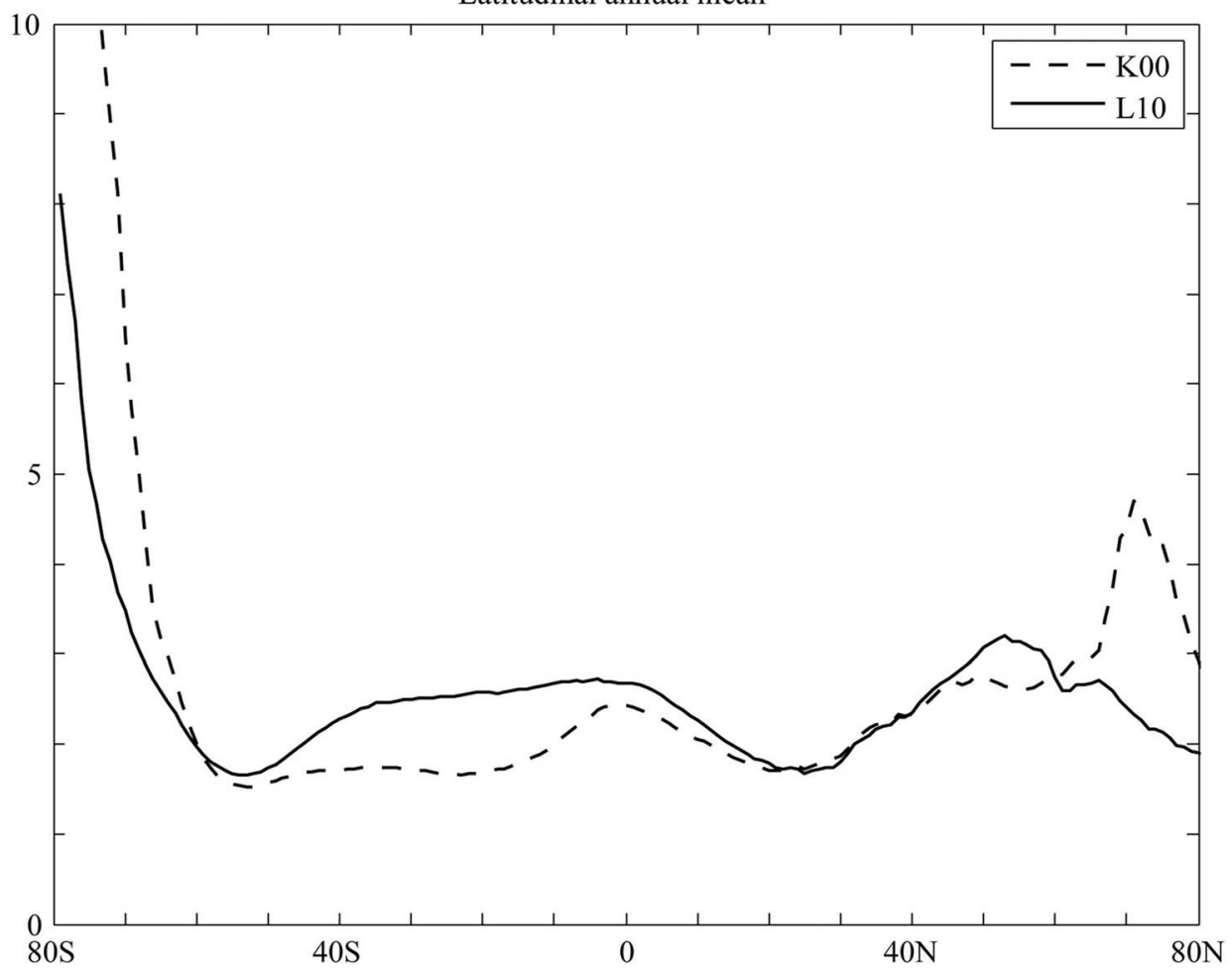

b)

January and July latitudinal mean

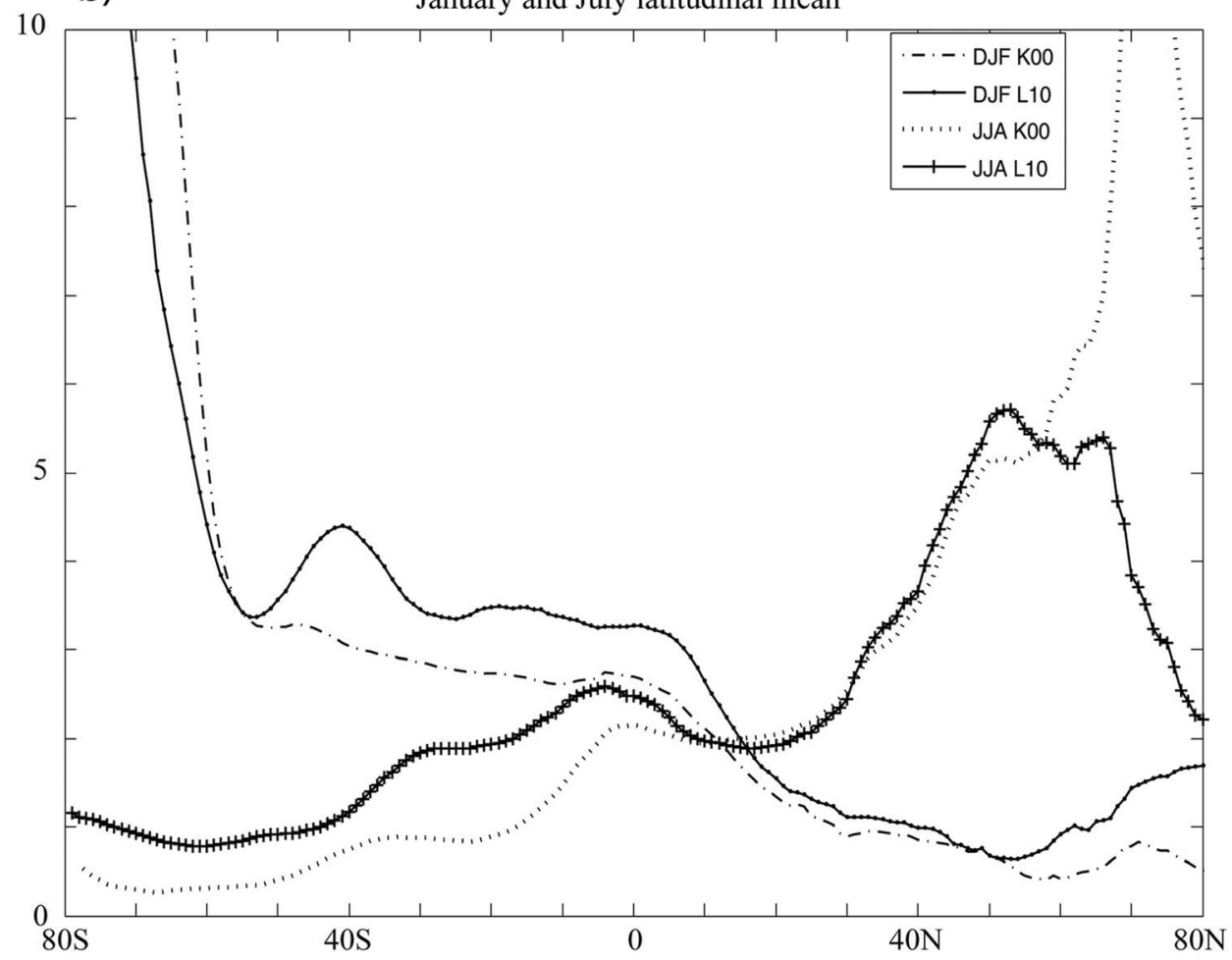

Figure 5. Comparison between K00 (dashed line) and L10 (solid line) climatological DMS concentration data (nM) in terms of (a) annual latitudinal mean concentrations; and (b) summer and winter (i.e., DJF, December-January-February; JJA, June-July-August) latitudinal mean concentrations. 
occurs between the equator and $40^{\circ} \mathrm{S}$, where new data in the Indian Ocean (MONS and ISSG) and Pacific Warm Pool (WARM) provinces raise the annual mean.

[50] The plot of the latitudinal seasonal means (Figure 5b) shows how DMS concentrations oscillate seasonally between lower values in the hemispheric winters and higher values in the hemispheric summers. The two climatologies predict almost identical concentrations in both seasons within the region comprised between $10^{\circ} \mathrm{N}$ and $50^{\circ} \mathrm{N}$. Figure $5 \mathrm{~b}$ clearly illustrates the substantial reduction in summer values and increase in winter values at both poles (i.e., greater than $60^{\circ} \mathrm{N}$ and $\mathrm{S}$ ), as well as the year-round increase between $10^{\circ} \mathrm{N}-50^{\circ} \mathrm{S}$, particularly in the Southern Hemisphere.

\subsection{DMS Flux}

[51] Local ocean-to-atmosphere DMS fluxes were computed from surface ocean concentrations using the parameterization suggested by Nightingale et al. [2000]; see section 2 . A climatological monthly sea ice mask was applied with the assumption that fluxes across the sea ice cover are greatly reduced or completely blocked, even though DMS concentrations measurements exist from the waters underneath. Emissions from the sea ice itself would also increase the amount of DMS fluxes to the atmosphere. Recent laboratory and in situ experiments [Zemmelink et al., 2008; Loose et al., 2009] indicate that gas emission can occur through or from complete or partial ice cover and this should be taken into account. However, this poses an obvious difficulty when we are to apply a general parameterization of the gas transfer coefficient. Computed fluxes with and without the ice cover mask, and the resulting global annual emissions, are not substantially different at the global scale $(9.8 \%$ higher without ice mask). The difference at high latitudes $\left(60^{\circ}-90^{\circ} \mathrm{N}\right.$ and $60^{\circ}-90^{\circ} \mathrm{S}$ ) is significant, $47.5 \%$ higher without the ice mask. The fluxes calculated here are capped by the use of an ice cover mask, but further work is required to better quantify the effect of sea ice on the sea-to-air flux of DMS.

[52] In northern latitudes, emission fluxes follow the seasonality of surface concentrations (see Figure 6). This is also true of the high latitudes in each hemispheric summer. The Southern Ocean emissions stand out because high summer concentrations coincide with strong winds all year round. In the subtropical Indian Ocean, the combination of moderate DMS concentrations and persistent high wind speeds throughout most of the year leads to a strong flux. The Pacific Warm Pool (WARM) fluxes are characterized by the coincidence of large concentrations and wind speeds between November and February, which renders high seasonal fluxes. In contrast, the waters East of Somalia, despite having quite constant predicted DMS concentrations throughout the year, become an important region of sulfur emissions during the boreal summer due to the strengthening winds caused by the southwest monsoon.

[53] Integrated DMS emission fluxes were computed using N00 and the classical parameterizations of Liss and Merlivat [1986] and Wanninkhof [1992], hereafter LM86 and W92, respectively. For the sake of comparison, and to provide a range of DMS flux estimates, we recalculated emissions for K00 with the three gas transfer parameterizations. Table 2 reports the results of annually integrated emissions by $10^{\circ}$ latitudinal bands resulting from applying the different parameterizations to K00 and L10.

[54] Annually integrated latitudinal emissions depend on the magnitude and persistence of local fluxes but also on the ocean area occupied by each latitudinal band. In K00, the tropics and Southern Ocean contribute the largest share of the global DMS emission. In L10, the southern subtropical latitudes also contribute substantially. Together, the Southern Hemisphere oceans contribute $61 \%-62 \%$ (depending on the parameterization) of the global annual DMS emissions in L10 whereas their contribution was around $56 \%-57 \%$ in K00. As a result of the differences in DMS concentration distribution discussed above, the global annual DMS emission in L10 is $15 \%-17 \%$ higher than that of K00. Taking $\mathrm{N} 00$ as an intermediate and probably more realistic parameterization of the transfer coefficient [Marandino et al., 2009], the updated revision of the global oceanic DMS emission is estimated at $28.1 \mathrm{TgS} / \mathrm{yr}$. Following the classification of Longhurst [1998] we computed the oceanic DMS emission fluxes from the coastal and upwelling areas. Nearly $11 \%$ of the global annual emissions occur in coastal provinces, which occupy nearly $10 \%$ of the global ocean area.

[55] Analysis of the variability in the underlying data used to construct the climatology shows that the range in total global flux estimates due to data variability is, at least, as large as the range due to uncertainty in the air/sea gas transfer velocity parameterization. DMS emission fluxes calculated by applying the N00 parameterization to the upper and lower bounds of the climatology uncertainty span a range of 24.1 to $40.4 \mathrm{TgS} / \mathrm{yr}$.

\section{Conclusions}

[56] The aim of this study was to construct a more accurate climatology of global monthly distributions of surfaceocean DMS concentration based on state-of-the-art data, and to calculate associated sea-to-air emission fluxes. The new L10 climatology has been constructed using data contributed by researchers from all over the world and archived in the Global Surface DMS Database (see Table S1), and can be regarded as an updated and refined version of the former climatology (K00) assembled by A.J. Kettle and others (K99 and K00).

[57] Climatological DMS concentrations increased in regions and months that were severely undersampled 10 years ago, as for example in the subtropical Indian Gyre. Conversely, data additions have substantially decreased climatological concentrations in regions where K99 showed extremely high values, namely polar waters. In this sense, a climatology constructed exclusively from available DMS measurements is very sensitive to the number of data, as pointed out by Belviso et al. [2004b]. Although the number of new DMS measurements in the Northern Hemisphere was around 50\% higher than that in the Southern Hemisphere, the largest differences between L10 and K00 are found in the South.

[58] Assessing the data coverage in oceanic provinces with the greatest areal extent (and consequently the largest 
January

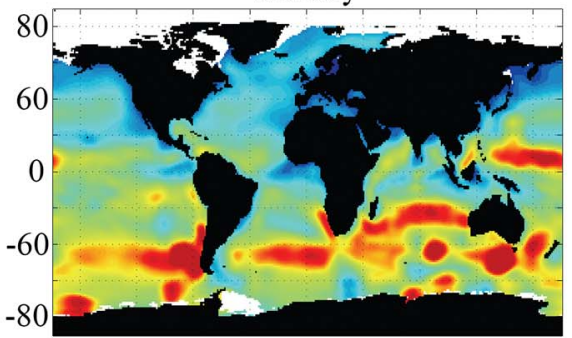

April

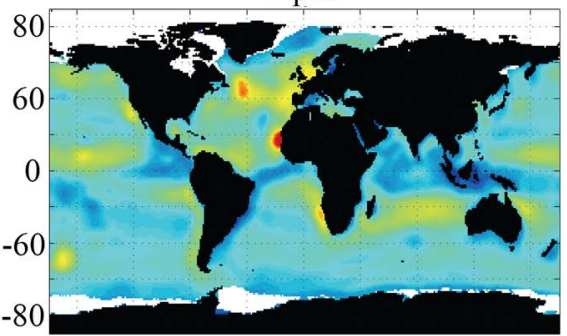

July

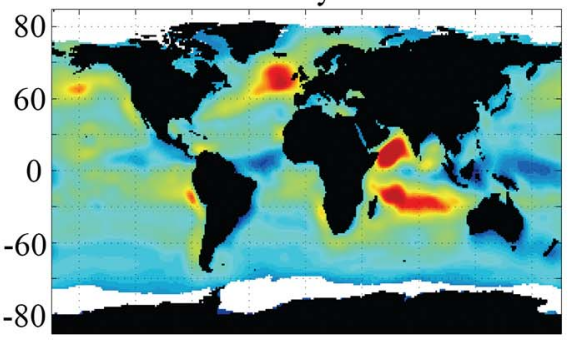

October

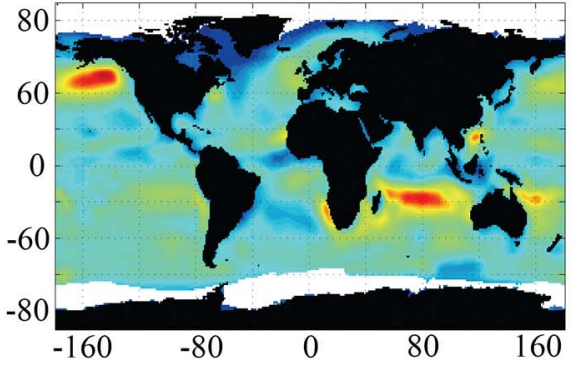

February

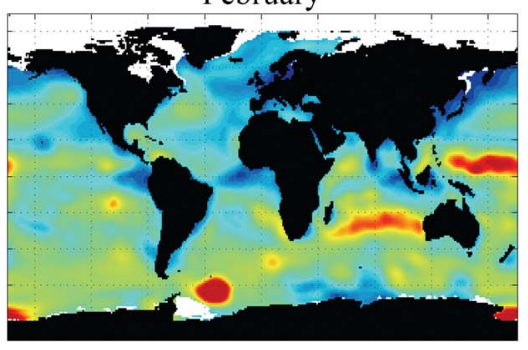

May

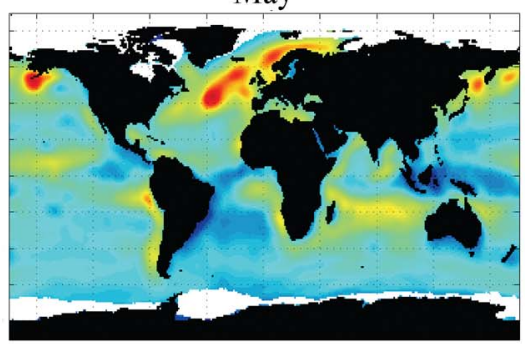

August

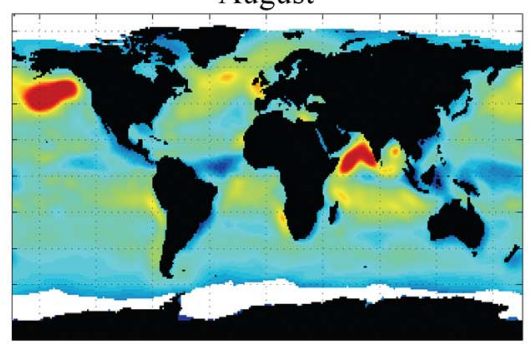

November

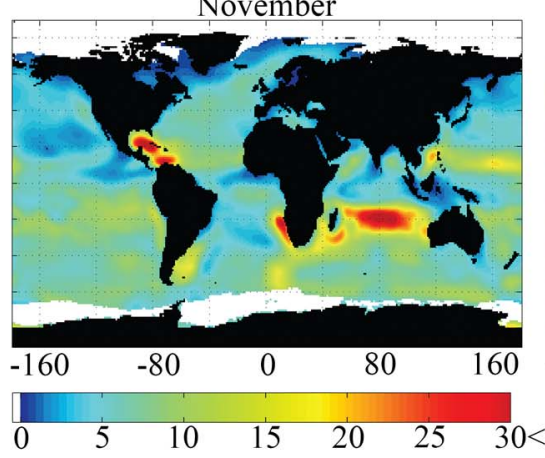

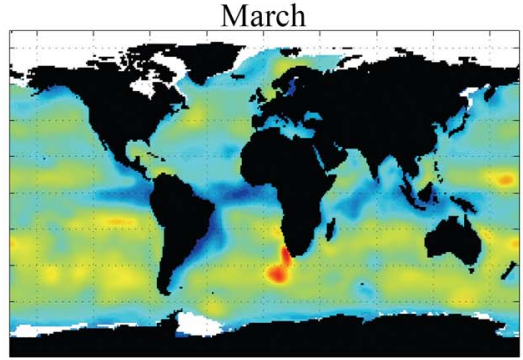

June

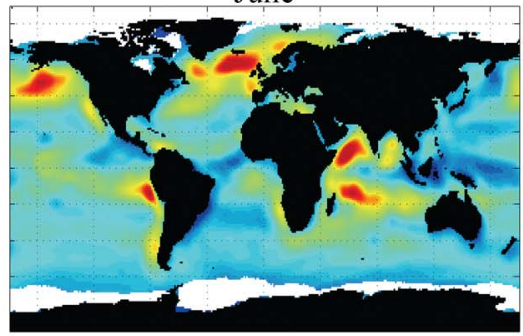

September

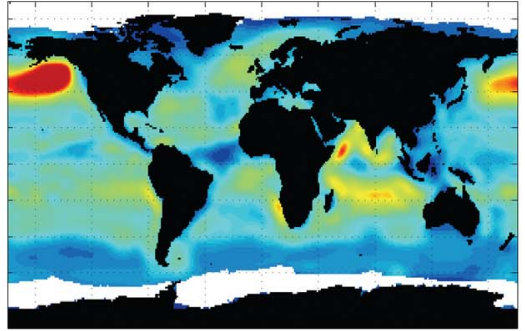

December

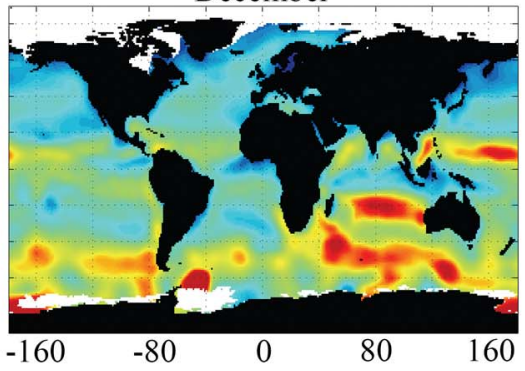

Figure 6. Monthly climatology of DMS fluxes $\left(\mu \mathrm{mol} \mathrm{S} / \mathrm{m}^{2} \mathrm{~d}\right)$. Note that the scale is capped at $30 \mu \mathrm{mol}$ $\mathrm{S} / \mathrm{m}^{2} \mathrm{~d}$ to ensure readability of the plots, although only a few specific regions exceed this value.

influence on DMS flux) has led to the realization that they are not always the most comprehensively sampled. In many cases, the measurements are poorly distributed in space and time (see Table 1). For example, the South Pacific Subtropical Gyre (SPSG) is undersampled despite containing data from eight calendar months. The data is sufficient to make a first-guess construction but only with a large associated uncertainty. Another example is the Indian Subtropical Gyre (ISSG), which still lacks data for half of the year despite a significant effort to increase the number of measurements in the last decade. Also the western North Pacific provinces, from the subarctic (PSAW) to the Tropical Gyre
(NPTW) through the Transition Zone (NPPF), show a serious lack of data relative to the surface area they represent. This means that the obtained climatological patterns have been constructed using interpolated data and should be used with caution and urgently revised as more measurements are made.

[59] The L10 climatology offers more reliable representation of sea surface DMS concentrations in the global oceans than the widely used former climatology (K00) mainly because of an increased number of measurements and improvements in their spatial and temporal coverage. It is expected to be used as an input field for global atmospheric 
Table 2. Annual DMS Flux (TgS/yr) per 10 Degree Latitudinal Band After This Study (L10) and the Kettle and Andreae [2000] (K00) Climatology, Computed With the Nightingale et al. [2000] Parameterization of the Piston Velocity ${ }^{\mathrm{a}}$

\begin{tabular}{|c|c|c|}
\hline Latitude & K00 & L10 \\
\hline & \multicolumn{2}{|c|}{ Nightingale et al. [2000] } \\
\hline $90^{\circ}-80^{\circ} \mathrm{N}$ & 0.0 & 0.0 \\
\hline $80^{\circ}-70^{\circ} \mathrm{N}$ & 0.2 & 0.1 \\
\hline $70^{\circ}-60^{\circ} \mathrm{N}$ & 0.2 & 0.2 \\
\hline $60^{\circ}-50^{\circ} \mathrm{N}$ & 0.7 & 0.9 \\
\hline $50^{\circ}-40^{\circ} \mathrm{N}$ & 1.4 & 1.5 \\
\hline $40^{\circ}-30^{\circ} \mathrm{N}$ & 1.5 & 1.5 \\
\hline $30^{\circ}-20^{\circ} \mathrm{N}$ & 1.4 & 1.4 \\
\hline $20^{\circ}-10^{\circ} \mathrm{N}$ & 2.4 & 2.6 \\
\hline $10^{\circ}-0^{\circ} \mathrm{N}$ & 2.3 & 2.6 \\
\hline $0^{\circ}-10^{\circ} \mathrm{S}$ & 1.9 & 2.2 \\
\hline $10^{\circ}-20^{\circ} \mathrm{S}$ & 2.3 & 3.5 \\
\hline $20^{\circ}-30^{\circ} \mathrm{S}$ & 1.9 & 3.0 \\
\hline $30^{\circ}-40^{\circ} \mathrm{S}$ & 1.9 & 2.7 \\
\hline $40^{\circ}-50^{\circ} \mathrm{S}$ & 2.4 & 2.8 \\
\hline $50^{\circ}-60^{\circ} \mathrm{S}$ & 2.0 & 2.1 \\
\hline $60^{\circ}-70^{\circ} \mathrm{S}$ & 1.2 & 0.9 \\
\hline $70^{\circ}-80^{\circ} \mathrm{S}$ & 0.2 & 0.1 \\
\hline $80^{\circ}-90^{\circ} \mathrm{S}$ & 0.0 & 0.0 \\
\hline \multirow[t]{3}{*}{ Total } & 24.0 & 28.1 \\
\hline & \multicolumn{2}{|c|}{ Liss and Merlivat [1986] } \\
\hline & K00 & L10 \\
\hline \multirow[t]{3}{*}{ Total } & 15.0 & 17.6 \\
\hline & \multicolumn{2}{|c|}{ Wanninkhof [1992] } \\
\hline & K00 & L10 \\
\hline Total & 29.4 & 34.4 \\
\hline
\end{tabular}

${ }^{\mathrm{a}}$ Total global DMS fluxes calculated using the Liss and Merlivat [1986] and Wanninkhof [1992] parameterizations are provided for comparison.

models and as a reference for global comparisons with oceanic and atmospheric variables. K00 has also been used to validate the output of oceanic DMS models [Le Clainche et al., 2010] despite the uncertainty associated with the data analysis. As a parallel product to the L10 climatology, we have created a $1^{\circ} \times 1^{\circ}$ binned monthly climatology of the original data which can be used for model validation (see http://www.bodc.ac.uk/solas integration/). This work confirms the central role of DMS in the transport of sulfur from the biosphere into the atmosphere. The updated estimates given here indicate that the annual global DMS emissions are even larger than previously thought, with our best estimate suggesting $28.1 \mathrm{TgS} / \mathrm{yr}(17 \%$ higher than estimated with K00). Owing to the potentially important influence of ocean-atmosphere DMS emissions for global sulfur cycling, aerosol formation, cloud microphysics, and radiative balance, the L10 will be useful for assessing the environmental factors controlling the DMS distribution and for validation of ocean biogeochemical models.

[60] Acknowledgments. The authors are indebted to each of the individual contributors that generously submitted their data to the Global Surface Seawater Dimethylsulfide Database (GSSDD) (see details in Table S1) and to T.S. Bates (NOAA/PMEL) for the maintenance and personal implication in the GSSDD. We thank the NCEP/NCAR Reanalysis Project for the production and free distribution of the SST and wind speed data used in the present work. We thank the Ocean Biology Processing Group at
GSFC for the production and distribution of the chlorophyll $a$ climatology, and Ocean Climate Laboratory at the NODC for the distribution of the World Ocean Atlas 2009 phosphate and nitrate's climatologies used in this study. We also wish to thank the Centre de Recherche et d'Exploitation Satellitaire (CERSAT), at IFREMER, Plouzané, France, for providing the Ice Climatology, and specially F. Girard-Ardhuin for her help with the data. A. Longhurst kindly provided the biogeographic provinces data. This work was the core of DiMethylSulfide concentrations and emission fluxes in the Global Ocean (DMS-GO), a joint initiative of the SOLAS Integration Project and the EU projects COST Action 735 and EUR-OCEANS. Tom Bell, Peter Liss, and SOLAS Project Integration are supported by a U.K. SOLAS Knowledge Transfer grant (NE/E001696/1). Further support was provided by the Spanish Ministry of Science and Innovation through the projects MIMOSA, Malaspina 2010, and a Ph.D. studentship to A.L.

\section{References}

Alvain, S., C. Moulin, Y. Dandonneau, and H. Loisel (2008), Seasonal distribution and succession of dominant phytoplankton groups in the global ocean: A satellite view, Global Biogeochem. Cycles, 22, GB3001, doi:10.1029/2007GB003154.

Anderson, T. R., S. A. Spall, A. Yool, P. Cipollini, P. G. Challenor, and M. J. R. Fasham (2001), Global fields of sea surface dimethylsulfide predicted from chlorophyll, nutrients and light, J. Mar. Syst., 30(1-2), $1-20$.

Andreae, M. O., and P. J. Crutzen (1997), Atmospheric aerosols: biogeochemical sources and role in atmospheric chemistry, Science, 276(5315), $1052-1058$

Andreae, M. O., and D. Rosenfeld (2008), Aerosol-cloud-precipitation interactions. Part 1. The nature and sources of cloud-active aerosols, Earth Sci. Rev., 89(1-2), 13-41, doi:10.1016/j.earscirev.2008.03.001.

Andreae, M. O., W. Elbert, and S. J. Demora (1995), Biogenic sulfur emissions and aerosols over the tropical South Atlantic: 3. Atmospheric dimethylsulfide, aerosols and cloud condensation nuclei, J. Geophys. Res., 100(D6), 11,335-11,356.

Archer, S. D., D. G. Cummings, C. A. Llewellyn, and J. R. Fishwick (2009), Phytoplankton taxa, irradiance and nutrient availability determine the seasonal cycle of DMSP in temperate shelf seas, Mar. Ecol. Prog. Ser., 394, 111-124, doi:10.3354/meps08284.

Aumont, O., S. Belviso, and P. Monfray (2002), Dimethylsulfoniopropionate (DMSP) and dimethylsulfide (DMS) sea surface distributions simulated from a global three-dimensional ocean carbon cycle model, J. Geophys. Res., 107(C4), 3029, doi:10.1029/1999JC000111.

Barnard, W. R., M. O. Andreae, and R. L. Iverson (1984), Dimethylsulfide and Phaeocystis poucheti in the southeastern Bering Sea, Cont. Shelf Res., 3(2), 103-113.

Barnes, S. L. (1964), A technique for maximizing details in numerical weather map analysis, J. Appl. Meteorol., 3(4), 396-409.

Barnes, S. L. (1994), Applications of the Barnes Objective Analysis Scheme. Part III: Tuning for minimum error, J. Atmos. Oceanic Technol., 11(6), 1459-1479.

Bates, T. S., and P. K. Quinn (1997), Dimethylsulfide (DMS) in the equatorial Pacific Ocean (1982 to 1996): Evidence of a climate feedback?, Geophys. Res. Lett., 24, 861-864.

Bates, T. S., B. K. Lamb, A. Guenther, J. Dignon, and R. E. Stoiber (1992), Sulfur emissions to the atmosphere from natural sources, J. Atmos. Chem., 14, 315-337.

Bell, T. G., G. Malin, C. M. McKee, and P. S. Liss (2006), A comparison of dimethylsulphide (DMS) data from the Atlantic meridional transect (AMT) programme with proposed algorithms for global surface DMS concentrations, Deep Sea Res. Part II, 53(14-16), 1720-1735, doi:10.1016/j. dsr2.2006.05.013

Belviso, S., and G. Caniaux (2009), A new assessment in North Atlantic waters of the relationship between DMS concentration and the upper mixed layer solar radiation dose, Global Biogeochem. Cycles, 23, GB1014, doi:10.1029/2008GB003382.

Belviso, S., C. Moulin, L. Bopp, and J. Stefels (2004a), Assessment of a global climatology of oceanic dimethylsulfide (DMS) concentrations based on SeaWiFS imagery (1998-2001), Can. J. Fish. Aquat. Sci., 61, 804-816, doi:10.1139/F04-001.

Belviso, S., et al. (2004b), Comparison of global climatological maps of sea surface dimethyl sulfide, Global Biogeochem. Cycles, 18, GB3013, doi:10.1029/2003GB002193.

Bopp, L., O. Aumont, S. Belviso, and S. Blain (2008), Modelling the effect of iron fertilization on dimethylsulphide emissions in the southern ocean, Deep Sea Res. Part II, 55(5-7), 901-912, doi:10.1016/j.dsr2.2007.12.002 Brimblecombe, P., and D. Shooter (1986), Photooxidation of dimethylsulfide in aqueous-solution, Mar. Chem., 19(4), 343-353. 
Carslaw, K. S., O. Boucher, D. V. Spracklen, G. W. Mann, J. G. L. Rae, S. Woodward, and M. Kulmala (2010), A review of natural aerosol interactions and feedbacks within the Earth system, Atmos. Chem. Phys., 10, 1701-1737.

Charlson, R. J., J. E. Lovelock, M. O. Andreae, and S. G. Warren (1987), Oceanic phytoplankton, atmospheric sulfur, cloud albedo and climate, Nature, 326(6114), 655-661.

Chu, S. P., S. Elliott, and M. E. Maltrud (2003), Global eddy permitting simulations of surface ocean nitrogen, iron, sulfur cycling, Chemosphere, $50(2), 223-235$.

Cressman, G. (1959), An operational objective analysis system, Mon Weather Rev., 87, 367-374.

Curran, M. A. J., G. B. Jones, and H. Burton (1998), Spatial distribution of dimethylsulfide and dimethylsulfoniopropionate in the Australasian sector of the Southern Ocean, J. Geophys. Res., 103, 16,677-16,689.

Dacey, J. W. H., S. G. Wakeham, and B. L. Howes (1984), Henry Law constants for dimethylsulfide in fresh-water and seawater, Geophys. Res. Lett., 11(10), 991-994.

Dacey, J. W. H., F. A. Howse, A. F. Michaels, and S. G. Wakeham (1998), Temporal variability of dimethylsulfide and dimethylsulfoniopropionate in the Sargasso Sea, Deep Sea Res., Part I, 45(12), 2085-2104.

Daley, R. (1993), Atmospheric Data Analysis, Cambridge Univ Press, Cambridge, U. K.

de Boyer Montégut, C., G. Madec, A. S. Fischer, A. Lazar, and D. Iudicone (2004), Mixed layer depth over the global ocean: An examination of profile data and a profile-based climatology, J. Geophys. Res., 109, C12003, doi:10.1029/2004JC002378.

del Valle, D. A., D. J. Kieber, D. A. Toole, J. Brinkley, and R. P. Kiene (2009), Biological consumption of dimethylsulfide (DMS) and its importance in DMS dynamics in the Ross Sea, Antarctica, Limnol. Oceanogr., 54(3), 785-798

Derevianko, G. J., C. Deutsch, and A. Hall (2009), On the relationship between ocean DMS and solar radiation, Geophys. Res. Lett., 36 , L17606, doi:10.1029/2009GL039412.

Devred, E., S. Sathyendranath, and T. Platt (2007), Delineation of ecological provinces using ocean colour radiometry, Mar. Ecol. Prog. Ser., 346 , 1-13, doi:10.3354/meps07149.

Elliott, S. (2009), Dependence of DMS global sea-air flux distribution on transfer velocity and concentration field type, J. Geophys. Res., 114, G02001, doi:10.1029/2008JG000710.

Fritsch, F. N., and R. E. Carlson (1980), Monotone piecewise cubic interpolation, SIAM J. Num. Anal., 17(2), 238-246.

Garcia, H. E., R. A. Locarnini, J. I. Antonov, and T. P. Boyer (2010), World Ocean Database 2009, NOAA Atlas NESDIS 71, edited by S. Levitus, U.S. Govt. Print. Off., Washington, D. C.

Hardman-Mountford, N. J., T. Hirata, K. A. Richardson, and J. Aiken (2008), An objective methodology for the classification of ecological pattern into biomes and provinces for the pelagic ocean, Remote Sens. Environ., 112(8), 3341-3352, doi:10.1016/j.rse.2008.02.016.

Howard, E. C., S. L. Sun, E. J. Biers, and M. A. Moran (2008), Abundant and diverse bacteria involved in DMSP degradation in marine surface waters, Environ. Microbiol., 10(9), 2397-2410, doi:10.1111/j.14622920.2008.01665.x

Iida, T., S. I. Saitoh, T. Miyamura, M. Toratani, H. Fukushima, and N. Shiga (2002), Temporal and spatial variability of coccolithophore blooms in the eastern Bering Sea, 1998-2001, Prog. Oceanogr., 55(1-2), 165-175.

Kettle, A. J., and M. O. Andreae (2000), Flux of dimethylsulfide from the oceans: A comparison of updated data seas and flux models, J. Geophys. Res., 105(D22), 26,793-26,808

Kettle, A. J., et al. (1999), A global database of sea surface dimethylsulfide (DMS) measurements and a procedure to predict sea surface DMS as a function of latitude, longitude, and month, Global Biogeochem. Cycles, 13(2), 399-444

Kiene, R. P., L. J. Linn, and J. A. Bruton (2000), New and important roles for DMSP in marine microbial communities, J. Sea Res., 43(3-4), 209-224.

Kloster, S., J. Feichter, E. M. Reimer, K. D. Six, P. Stier, and P. Wetze (2006), DMS cycle in the marine ocean-atmosphere system: A global model study, Biogeosciences, 3(1), 29-51.

Koch, S. E., M. desJardins, and P. J. Kocin (1983), An interactive Barnes Objective Map Analysis Scheme for use with satellite and conventional data, J. Appl. Meteorol., 22(9), 1487-1503.

Kondo, J. (1975), Air-sea bulk transfer coefficients in diabatic conditions, J. Meteorol., 9, 91-112.

Le Clainche, Y., et al. (2010), A first appraisal of prognostic ocean DMS models and prospects for their use in climate models, Global Biogeochem. Cycles, 24, GB3021, doi:10.1029/2009GB003721.
Lee, G., J. Park, Y. Jang, M. Lee, K.-R. Kim, J.-R. Oh, D. Kim, H.-I. Yi, and T.-Y. Kim (2010), Vertical variability of seawater DMS in the South Pacific Ocean and its implication for atmospheric and surface seawater DMS, Chemosphere, 78(8), 1063-1070, doi:10.1016/j. chemosphere.2009.10.054.

Liss, P., and L. Merlivat (1986), Air-sea gas exchange rates: Introduction and synthesis, in The Role of Air-Sea Exchange in Geochemical Cycling, edited by P. Buat-Ménard, pp. 113-128, D. Reidel, Dordrecht, Netherlands.

Liss, P. S., and P. G. Slater (1974), Flux of gases across air-sea interface, Nature, 247, 181-184.

Liss, P. S., A. L. Chuck, S. M. Turner, and A. J. Watson (2004), Air-sea gas exchange in Antarctic waters, Antarct. Sci., 16(4), 517-529, doi:10.1017/S0954102004002299.

Lizotte, M., M. Levasseur, M. G. Scarratt, S. Michaud, A. Merzouk, M. Gosselin, and J. Pommier (2008), Fate of dimethylsulfoniopropionate (DMSP) during the decline of the northwest Atlantic Ocean spring diatom bloom, Aquat. Microbial Ecol., 52, 159-173, doi:10.3354/ame01232.

Locarnini, R., A. Mishonov, J. Antonov, T. Boyer, and H. Garcia (2010), World Ocean Database 2009, NOAA Atlas NESDIS 68, edited by S. Levitus, U.S. Govt. Print. Off., Washington, D. C.

Longhurst, A. (1998), Ecological Geography of the Sea, Acad. Press, London.

Longhurst, A. (2007), Ecological Geography of the Sea, 2nd ed., Acad. Press, Burlington, Mass.

Loose, B., W. R. McGillis, P. Schlosser, D. Perovich, and T. Takahashi (2009), Effects of freezing, growth, and ice cover on gas transport processes in laboratory seawater experiments, Geophys. Res. Lett., 36, L05603, doi:10.1029/2008GL036318.

Marandino, C. A., W. J. De Bruyn, S. D. Miller, and E. S. Saltzman (2009), Open ocean DMS air/sea fluxes over the eastern South Pacific Ocean, Atmos. Chem. Phys., 9(2), 345-356.

Matrai, P. A., and M. D. Keller (1993), Dimethylsulfide in a large-scale Coccolithophore bloom in the Gulf Of Maine, Cont. Shelf Res., 13, 831-843.

Matrai, P., M. Vernet, and P. Wassmann (2007), Relating temporal and spatial patterns of DMSP in the Barents Sea to phytoplankton biomass and productivity, J. Mar. Syst., 67(1-2), 83-101, doi:10.1016/j. jmarsys.2006.10.001

McGillis, W. R., J. W. H. Dacey, N. M. Frew, E. J. Bock, and R. K. Nelson (2000), Water-air flux of dimethylsulfide, J. Geophys. Res., 105(C1), 1187-1193.

McTaggart, A. R., and H. Burton (1992), Dimethyl Sulfide concentrations in the surface waters of the Australasian Antarctic and Subantarctic Oceans during an austral summer, J. Geophys. Res., 97, 14,407-14,4412.

Miles, C. J., T. G. Bell, and T. M. Lenton (2009), Testing the relationship between the solar radiation dose and surface DMS concentrations using in situ data, Biogeosciences, 6, 1927-1934.

Nightingale, P. D., G. Malin, C. S. Law, A. J. Watson, P. S. Liss, M. I. Liddicoat, J. Boutin, and R. C. Upstill-Goddard (2000), In situ evaluation of air-sea gas exchange parameterizations using novel conservative and volatile tracers, Global Biogeochem. Cycles, 14(1), 373-387.

Oliver, M. J., and A. J. Irwin (2008), Objective global ocean biogeographic provinces, Geophys. Res. Lett., 35, L15601, doi:10.1029/2008GL034238.

Pérez, V., E. Fernandez, E. Maranon, P. Serret, and C. Garcia-Soto (2005), Seasonal and interannual variability of chlorophyll $a$ and primary production in the equatorial Atlantic: In situ and remote sensing observations, J. Plankton Res., 27(2), 189-197.

Saltzman, E. S., D. B. King, K. Holmen, and C. Leck (1993), Experimental determination of the diffusion coefficient of Dimethylsulfide in water, J. Geophys. Res., 98(C9), 16,481-16,486.

Saltzman, E. S., W. J. De Bruyn, M. J. Lawler, C. A. Marandino, and C. A. McCormick (2009), A chemical ionization mass spectrometer for continuous underway shipboard analysis of dimethylsulfide in near-surface seawater, Ocean Sci., 5(4), 537-546.

Scarratt, M. G., M. Levasseur, S. Michaud, and S. Roy (2007), DMSP and DMS in the Northwest Atlantic: Late-summer distributions, production rates and sea-air fluxes, Aquat Sci, 69, 292-304, doi:10.1007/s00027007-0886-1.

Shenoy, D. M., and M. D. Kumar (2007), Variability in abundance and fluxes of dimethyl sulphide in the Indian Ocean, Biogeochemistry, 83(1-3), 277-292, doi:10.1007/s10533-007-9092-4.

Shuman, F. G. (1957), Numerical methods in weather prediction: II. Smoothing and filtering, Mon. Weather Rev., 85(11), 357-361.

Simó, R. (2001), Production of atmospheric sulfur by oceanic plankton: biogeochemical, ecological and evolutionary links, Trends Ecol. Evol., 16(6), 287-294. 
Simó, R., and J. Dachs (2002), Global ocean emission of dimethylsulfide predicted from biogeophysical data, Global Biogeochem. Cycles, 16(4), 1018, doi:10.1029/2001GB001829.

Simó, R., and C. Pedrós-Alió (1999), Role of vertical mixing in controlling the oceanic production of dimethyl sulphide, Nature, 402(6760), 396-399.

Six, K. D., and E. Maier-Reimer (2006), What controls the oceanic dimethylsulfide (DMS) cycle? A modeling approach, Global Biogeochem. Cycles, 20, GB4011, doi:10.1029/2005GB002674.

Stefels, J., and L. Dijkhuizen (1996), Characteristics of DMSP-lyase in Phaeocystis sp (prymnesiophyceae), Mar. Ecol. Prog. Ser., 131(1-3), 307-313.

Stefels, J., M. Steinke, S. Turner, G. Malin, and S. Belviso (2007), Environmental constraints on the production and removal of the climatically active gas dimethylsulphide (DMS) and implications for ecosystem modelling, Biogeochemistry, 83(1-3), 245-275, doi:10.1007/s10533-007-9091-5.

Toole, D. A., D. J. Kieber, R. P. Kiene, D. A. Siegel, and N. B. Nelson (2003), Photolysis and the dimethylsulfide (DMS) summer paradox in the Sargasso Sea, Limnol. Oceanogr., 48(3), 1088-1100.

Trevena, A. J., and G. B. Jones (2006), Dimethylsulphide and dimethylsulphoniopropionate in Antarctic sea ice and their release during sea ice melting, Mar. Chem., 98(2-4), 210-222, doi:10.1016/j.marchem. 2005.09.005.

Vallina, S. M., and R. Simó (2007), Strong relationship between DMS and the solar radiation dose over the global surface ocean, Science, 315(5811), 506-508, doi:10.1126/science. 1133680 .

Vila-Costa, M., R. Simó, H. Harada, J. M. Gasol, D. Slezak, and R. P. Kiene (2006), Dimethylsulfoniopropionate uptake by marine phytoplankton, Science, 314(5799), 652-654, doi:10.1126/science.1131043.

Vila-Costa, M., J. Pinhassi, C. Alonso, J. Pernthaler, and R. Simó (2007), An annual cycle of dimethylsulfoniopropionate-sulfur and leucine assimilating bacterioplankton in the coastal NW Mediterranean, Environ. Microbiol., 9(10), 2451-2463, doi:10.1111/j.1462-2920.2007.01363.x.

Vogt, M., S. M. Vallina, E. T. Buitenhuis, L. Bopp, and C. Le Quere (2010), Simulating Dimethylsulphide seasonality with the Dynamic Green Ocean Model PlankTOM5, J. Geophys. Res., 115, C06021, doi:10.1029/2009JC005529.

Wanninkhof, R. (1992), Relationship between wind speed and gas exchange over the ocean, J. Geophys. Res., 97, 7373-7382.

Wong, C. S., S. E. Wong, W. A. Richardson, G. E. Smith, M. D. Arychuk, and J. S. Page (2005), Temporal and spatial distribution of dimethylsul- fide in the subarctic northeast Pacific Ocean: A high-nutrient-lowchlorophyll region, Tellus, Ser. B, 57(4), 317-331.

Yang, G. P., M. Levasseur, S. Michaud, A. Merzouk, M. Lizotte, and M. Scarratt (2009), Distribution of dimethylsulfide and dimethylsulfoniopropionate and its relation with phytoneuston in the surface microlayer of the western North Atlantic during summer, Biogeochemistry, 94, 243-254, doi:10.1007/s10533-009-9323-y.

Yoch, D. C. (2002), Dimethylsulfoniopropionate: its sources, role in the marine food web, and biological degradation to dimethylsulfide, Appl. Environ. Microbiol., 68(12), 5804-5815, doi:10.1128/AEM.68.12.58045815.2002.

Zemmelink, H. J., J. W. H. Dacey, L. Houghton, E. J. Hintsa, and P. S. Liss (2008), Dimethylsulfide emissions over the multi-year ice of the western Weddell Sea, Geophys. Res. Lett., 35(6), L06603, doi:10.1029/ 2007GL031847.

J. Ballabrera-Poy, A. Lana, and R. Simó, ICM, CSIC, P. Marítim de la Barceloneta 37-49, Barcelona E-08003, Catalonia, Spain (joaquim@icm. csic.es; lana@cmima.csic.es; rsimo@icm.csic.es)

T. G. Bell and P. S. Liss, School of Environmental Sciences, University of East Anglia, NR4 7TJ Norwich, UK. (thomas.bell@uea.ac.uk; p.liss@ uea.ac.uk)

L. Bopp, LSCE, IPSL, CNRS, CEA, UVSQ, Bat 712, Orme des Merisiers, CE Saclay, F-91191 Gif sur Yvette, France. (laurent.bopp@ 1sce.ipsl.fr)

J. Dachs, IDAEA, CSIC, Jordi Girona 18-26, Barcelona E-08034, Catalonia, Spain. (jdmqam@cid.csic.es)

J. E. Johnson, NOAA Pacific Marine Environmental Laboratory, 7600 Sand Pt. Way NE, Seattle, WA 98115, USA. (james.e.johnson@noaa.gov) A. J. Kettle, Department of Earth Sciences, SUNY-Oswego, Oswego, NY 13126, USA. (kettle@oswego.edu)

E. S. Saltzman, School of Physical Sciences, University of California, 3325 Croul Hall, Irvine, CA 92697, USA. (esaltzma@uci.edu)

J. Stefels, Laboratory of Plant Physiology, University of Groningen, Kerklaan 30, NL-9751 NN Haren, Netherlands. (j.stefels@rug.nl)

S. M. Vallina, EAPS, MIT, 77 Massachusetts Ave., Cambridge, MA 02139, USA. (vallina@mit.edu) 